\title{
AUGMENTER OF LIVER REGENERATION: A FLAVIN-DEPENDENT SULFHYDRYL OXIDASE WITH CYTOCHROME $C$ REDUCTASE ACTIVITY
}

by

Scott Farrell

A thesis submitted to the Faculty of the University of Delaware in partial fulfillment of the requirements for Master of Science in Chemistry and Biochemistry

Spring 2013

(C) 2013 Scott Farrell

All Rights Reserved 


\section{AUGMENTER OF LIVER REGENERATION A FLAVIN-DEPENDENT SULFHYDRYL OXIDASE WITH CYTOCHROME $C$ REDUCTASE ACTIVITY}

by

Scott Farrell

Approved:

Colin Thorpe, Ph.D.

Professor in charge of thesis on behalf of the Advisory Committee

Approved:

Murray V. Johnston, Ph.D.

Chair of the Department of Department Chemistry and Biochemistry

Approved:

George H. Watson, Ph.D

Dean of the College of Arts and Science

Approved:

James G. Richards, Ph.D.

Vice Provost for Graduate and Professional Education 


\section{ACKNOWLEDGMENTS}

I would first like to thank my advisor, Dr. Colin Thorpe, for giving me an unique perspective on not only biochemistry but on life. His patience, persistence and dedication has helped me see the project through. I will always remember the days that we had to stare at the enzyme cross-eyed in order for it to behave. I would also like to thank the faculty and staff of University of Delaware for without whom none of this would be possible.

A special acknowledgement is for my daughter, Gracie. Even before the first time I held her in my arms, she has been my diving force to succeed. She is my inspiration and when I look at her, I feel the desire to improve upon myself and become better not only as a scientist but as person overall. In her own way, she encourages me to keep striving for the next level and prepare myself for whatever comes next. 


\section{TABLE OF CONTENTS}

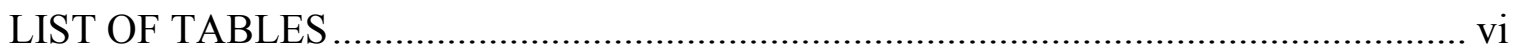

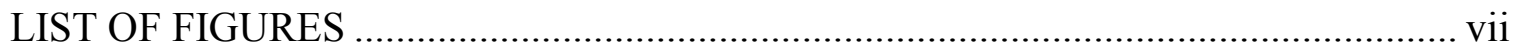

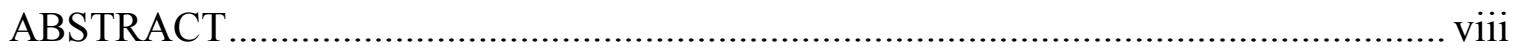

Chapter

1 INTRODUCTION TO SULFHYDRYL OXIDASES ..........................................

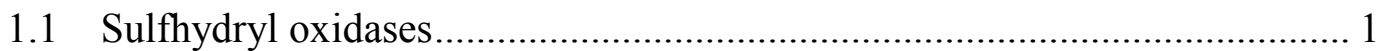

1.2 Sulfhydryl oxidases: cellular locations .................................................... 3

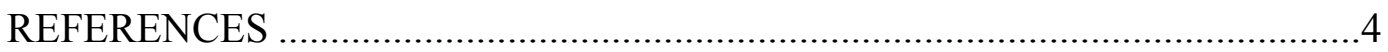

2 PURIFICATION AND CHARACTERIZATION OF AUGMENTER OF

LIVER REGENERATION...........................................................................

$2.1 \quad$ Experimental Procedures ………………………................................... 7

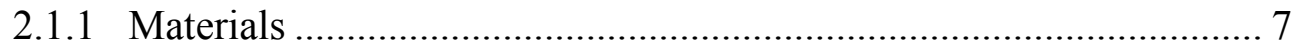

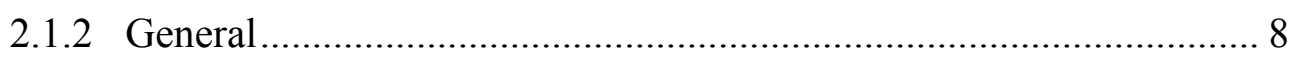

2.1.3 Determination of Midpoint Potentials ............................................... 8

2.1.4 Enzyme Assays ........................................................................ 9

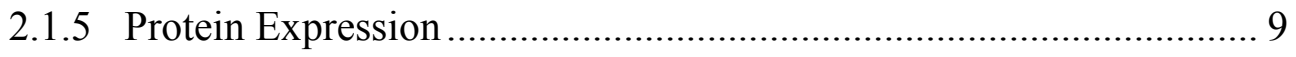

2.1.6 Preparation of Cellular Extract ........................................................ 10

2.1.7 Refolding of Long Peptide Linker ALR ........................................... 10

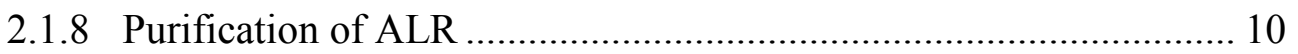


2.1.9 Mutation Studies of ALR ......................................................... 11

2.1.10 Isolation of ALR Peptides........................................................ 11

2.1.11 Stopped-Flow Spectrophotometry …..................................... 12

2.2 Results and Discussion ................................................................. 12

2.2.1 Construction Expression, and Purification of Human ALR........... 12

2.2.2 Preliminary Characterization of Human ALR ............................. 13

2.2.3 Homology Model and Disulfide Connectivity in Human ALR....... 15

2.2.4 DTT Oxidase Activity of the Thiol Mutant of ALR....................... 22

2.2.5 Rationale for Using the C74A/C85A Double Mutant of Human

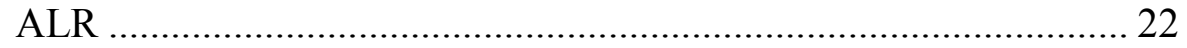

2.2.6 Dithionite Titrations of ALR ....................................................... 23

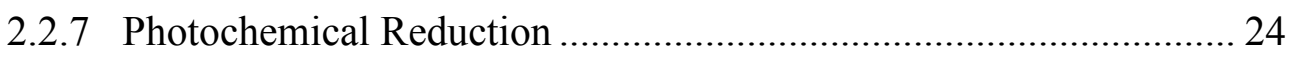

2.2.8 DTT Reduction under Anaerobic and Aerobic Turnover Conditions............................................................................. 26

2.2.9 A New Enzymatic Activity for ALR ......................................... 31

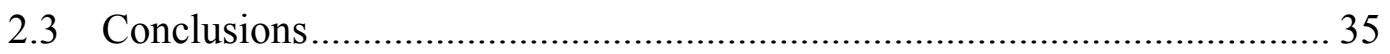

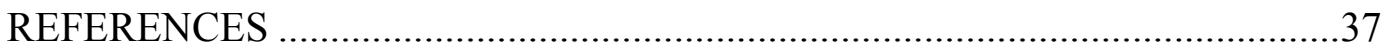




\section{LIST OF TABLES}

Table 2.1: DTT Oxidase Activity of Wild Type and Selected Cysteine Mutants of Human ALR ..................................................................................... 19 


\section{LIST OF FIGURES}

Figure 1.1: $\quad$ Sequence alignment of selected ALR, ERV and QSOX proteins................ 2

Figure 2.1: UV/VIS spectrum of recombinant human ALR ................................... 14

Figure 2.2: Homology model of human short-form ALR based on the crystal structure

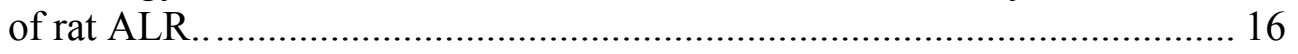

Figure 2.3: Cysteine residues and disulfide connectivity of human ALR .................... 17

Figure 2.4: SDS-PAGE of recombinant wild-type ALR and selected cysteine to alanine mutants.......................................................................... 21

Figure 2.5: Dithionite titration of the C74A/C85A double-mutant of human ALR. ..... 25

Figure 2.6: Redoxidation of photochemically reduced human ALR........................... 27

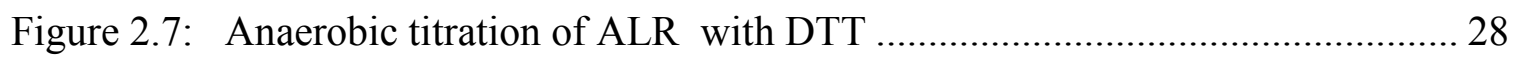

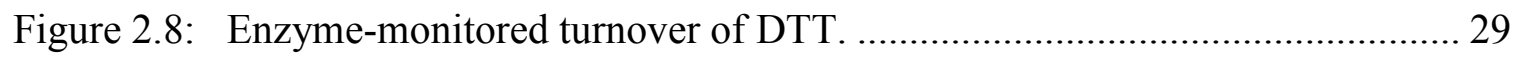

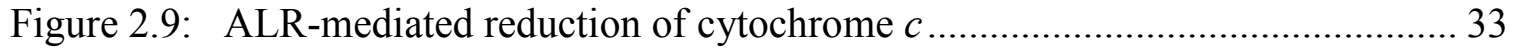

Figure 2.10: Cytochrome $\mathrm{c}$ inhibits oxygen consumption by ALR ............................. 34 


\begin{abstract}
Augmenter of Liver Regeneration (ALR; hepatopoietin) has been studied as a flavin-linked sulfhydryl oxidase. Several lines of evidence suggest that human ALR is a disulfide-bridged dimer (linked via C15-C124) with two free cysteine residues (C74 and $85)$ per monomer. Here I will show that the C15-C124 disulfides are not critical for dimer formation and have insignificant impact on the dithiothreitol (DTT) oxidase activity of ALR. Although the crystal structure of rat ALR shows a proximal disulfide (C62-C65) poised to interact with the FAD prosthetic group [Wu, C. K., Dailey, T. A., Dailey, H. A., Wang, B. C., and Rose, J. P. (2003) Protein Sci. 12, 1109-18] only flavin reduction is evident during redox titrations of the enzyme. ALR forms large amounts of the neutral flavosemiquinone during aerobic turnover with DTT. This semiquinone arises, in part, by comproportionation between flavin centers within the dimer. Surprisingly cytochrome $c$ is about a 100-fold better electron acceptor for ALR than oxygen when DTT is the reducing substrate. Herein we discuss that this poorly understood flavoenzyme may not function as a sulfhydryl oxidase within the mitochondrial intermembrane space, but may communicate with the respiratory chain via the mediation of cytochrome $c$.
\end{abstract}




\section{Chapter 1}

\section{INTRODUCTION TO SULFHYDRYL OXIDASES}

\subsection{Sulfhydryl oxidases}

Sulfhydryl oxidases catalyze the formation of disulfide bonds at the expense of molecular oxygen [1-6]:

$$
2 \mathrm{R}-\mathrm{SH}+\quad \mathrm{O}_{2} \quad \rightarrow \quad \text { R-S-S-R } \quad+\quad \mathrm{H}_{2} \mathrm{O}_{2}
$$

Quiescin-like flavin-dependent sulfhydryl oxidase (QSOX) enzymes are found in all multicellular organisms investigated to date [6-10]. These proteins represent an ancient fusion [9] of thioredoxin modules with a domain termed ERV [essential for respiration and vegetative growth in yeast [11] or ALR [augmenter of liver regeneration $[12,13]$. A comparison of several sequences of this domain is presented in figure 1.1 . 


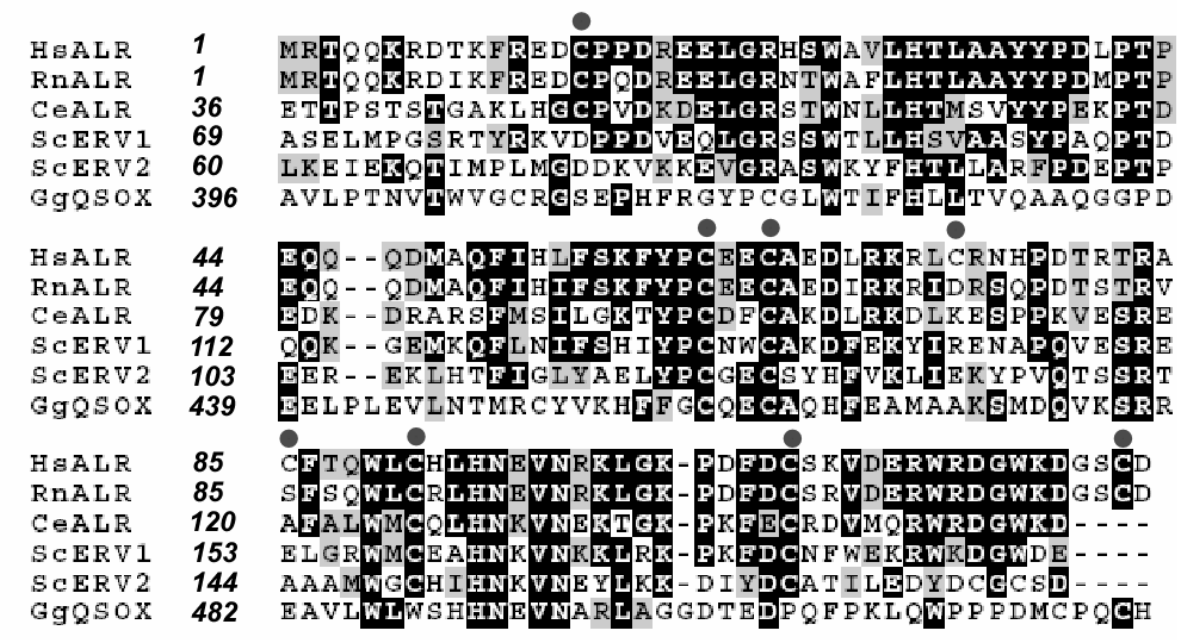

Figure 1.1: Sequence alignment of selected ALR, ERV and QSOX proteins. Representative sequences of proteins homologous to ERV/ALR domains are chosen: human (Hs), rat ( $\mathrm{Rn})$ and Caenorhabditis elegans (Ce) ALR, Saccharomyces cerevisae (Sc) ERV1p and ERV2p and Gallus gallus (Gg) QSOX. Boxshade was used for alignment. Cysteine residues in hsALR are highlighted with solid circles.

Following the recognition that quiescin Q6 was a flavin dependent sulfhydryl oxidase [10], yeast ERV1p and ERV2p [14-18] and mammalian ALR [19] were found to be diminutive FAD-linked sulfhydryl oxidases. Crystal structures of the ERV2 [20] and ALR [21] revealed a new helix-rich fold that houses the core sulfhydryl oxidase activity with a FAD binding site and a conserved proximal CxxC motif adjacent to the isoalloxazine ring. While ERV1p, ERV2p and ALR appear to be relatively weak stand-alone sulfhydryl oxidases [14, 16, 18-20], the fusion with two thioredoxin domains in QSOX generates a facile, direct, catalyst for oxidation of a seemingly unlimited array of reduced proteins and peptides [6, 22-24]. 


\subsection{Sulfhydryl oxidases: cellular locations}

These sulfhydryl oxidases have a range of cellular locations. QSOX enzymes have been reported in the ER of multicellular organisms [6,7], within the Golgi [25], at the plasma and nuclear membranes [7], and secreted from the cell [6, 8, 26, 27]. ERV2p is found largely in the ER of yeast $[15,18,28]$ where it participates in oxidative protein folding. In contrast, ALR is located primarily in the mitochondrial intermembrane space, as is its direct counterpart in yeast (the essential protein ERV1p) [17, 29, 30]. At this location, ERV1p is involved in some aspect of the assembly or trafficking in $\mathrm{Fe} / \mathrm{S}$ centers destined for cytosolic $\mathrm{Fe} / \mathrm{S}$ proteins [17]. Mammalian ALR has also been found in the cytosol [31], in the nucleus $[31,32]$ and as a secreted growth factor [33-36]. ALR appears to have multiple roles in the regulation of cell growth and differentiation $[17,19,30,33-35$, $37,38]$. 


\section{REFERENCES}

1. Janolino, V.G. and H.E. Swaisgood, Isolation and characterization of sulfhydryl oxidase from bovine milk. J Biol Chem, 1975. 250(7): p. 2532-8.

2. Lash, L.H., D.P. Jones, and S. Orrenius, The renal thiol (glutathione) oxidase. Subcellular localization and properties. Biochim Biophys Acta, 1984. 779(2): p. 191-200.

3. de la Motte, R.S. and F.W. Wagner, Aspergillus niger sulfhydryl oxidase. Biochemistry, 1987. 26(23): p. 7363-71.

4. Ostrowski, M.C. and W.S. Kistler, Properties of a flavoprotein sulfhydryl oxidase from rat seminal vesicle secretion. Biochemistry, 1980. 19(12): p. 2639-45.

5. Hoober, K.L., et al., A sulfhydryl oxidase from chicken egg white. J Biol Chem, 1996. 271(48): p. 30510-6.

6. Thorpe, C., et al., Sulfhydryl oxidases: emerging catalysts of protein disulfide bond formation in eukaryotes. Arch Biochem Biophys, 2002. 405(1): p. 1-12.

7. Wittke, I., et al., Neuroblastoma-derived sulfhydryl oxidase, a new member of the sulfhydryl oxidase/Quiescin6 family, regulates sensitization to interferon gamma-induced cell death in human neuroblastoma cells. Cancer Res, 2003. 63(22): p. 7742-52.

8. Benayoun, B., et al., Rat seminal vesicle FAD-dependent sulfhydryl oxidase. Biochemical characterization and molecular cloning of a member of the new sulfhydryl oxidase/quiescin Q6 gene family. J Biol Chem, 2001.

276(17): p. 13830-7.

9. Coppock, D.L., D. Cina-Poppe, and S. Gilleran, The quiescin Q6 gene (QSCN6) is a fusion of two ancient gene families: thioredoxin and ERV1. Genomics, 1998. 54(3): p. 460-8.

10. Hoober, K.L., et al., Homology between egg white sulfhydryl oxidase and quiescin Q6 defines a new class of flavin-linked sulfhydryl oxidases. J Biol Chem, 1999. 274(45): p. 31759-62.

11. Lisowsky, T., Dual function of a new nuclear gene for oxidative phosphorylation and vegetative growth in yeast. Mol Gen Genet, 1992. 232(1): p. 58-64.

12. Hagiya, M., et al., Cloning and sequence analysis of the rat augmenter of liver regeneration (ALR) gene: expression of biologically active recombinant ALR and demonstration of tissue distribution. Proc Natl Acad Sci U S A, 1994. 91(17): p. 8142-6. 
13. Polimeno, L., T. Lisowsky, and A. Francavilla, From yeast to man--from mitochondria to liver regeneration: a new essential gene family. Ital J Gastroenterol Hepatol, 1999. 31(6): p. 494-500.

14. Hofhaus, G., et al., The N-terminal cysteine pair of yeast sulfhydryl oxidase Ervlp is essential for in vivo activity and interacts with the primary redox centre. Eur J Biochem, 2003. 270(7): p. 1528-35.

15. Gerber, J., et al., Yeast ERV2p is the first microsomal FAD-linked sulfhydryl oxidase of the Ervlp/Alrp protein family. J Biol Chem, 2001. 276(26): p. 23486-91.

16. Lee, J., G. Hofhaus, and T. Lisowsky, Ervlp from Saccharomyces cerevisiae is a FAD-linked sulfhydryl oxidase. FEBS Lett, 2000. 477(1-2): p. 62-6.

17. Lange, H., et al., An essential function of the mitochondrial sulfhydryl oxidase Erv1p/ALR in the maturation of cytosolic Fe/S proteins. EMBO Rep, 2001. 2(8): p. 715-20.

18. Sevier, C.S., et al., A flavoprotein oxidase defines a new endoplasmic reticulum pathway for biosynthetic disulphide bond formation. Nat Cell Biol, 2001. 3(10): p. 874-82.

19. Lisowsky, T., et al., Mammalian augmenter of liver regeneration protein is a sulfhydryl oxidase. Dig Liver Dis, 2001. 33(2): p. 173-80.

20. Gross, E., et al., A new FAD-binding fold and intersubunit disulfide shuttle in the thiol oxidase Erv2p. Nat Struct Biol, 2002. 9(1): p. 61-7.

21. Wu, C.K., et al., The crystal structure of augmenter of liver regeneration: $A$ mammalian FAD-dependent sulfhydryl oxidase. Protein Sci, 2003. 12(5): p. 1109-18.

22. Hoober, K.L., et al., Sulfhydryl oxidase from egg white. A facile catalyst for disulfide bond formation in proteins and peptides. J Biol Chem, 1999. 274(32): p. 22147-50.

23. Hoober, K.L. and C. Thorpe, Egg white sulfhydryl oxidase: kinetic mechanism of the catalysis of disulfide bond formation. Biochemistry, 1999. 38(10): p. 3211-7.

24. Hoober, K.L. and C. Thorpe, Flavin-dependent sulfhydryl oxidases in protein disulfide bond formation. Methods Enzymol, 2002. 348: p. 30-4.

25. Mairet-Coello, G., et al., FAD-linked sulfhydryl oxidase QSOX: topographic, cellular, and subcellular immunolocalization in adult rat central nervous system. J Comp Neurol, 2004. 473(3): p. 334-63.

26. Amiot, C., et al., Expression of the secreted FAD-dependent sulfydryl oxidase (QSOX) in the guinea pig central nervous system. Brain Res Mol Brain Res, 2004. 125(1-2): p. 13-21.

27. Coppock, D., et al., Regulation of the quiescence-induced genes: quiescin Q6, decorin, and ribosomal protein S29. Biochem Biophys Res Commun, 2000. 269(2): p. 604-10.

28. Sevier, C.S. and C.A. Kaiser, Formation and transfer of disulphide bonds in living cells. Nat Rev Mol Cell Biol, 2002. 3(11): p. 836-47. 
29. Becher, D., et al., A mutant for the yeast scERV1 gene displays a new defect in mitochondrial morphology and distribution. Yeast, 1999. 15(12): p. 1171-81.

30. Klissenbauer, M., et al., Accumulation of the mitochondrial form of the sulphydryl oxidase Erv1p/Alrp during the early stages of spermatogenesis. $\mathbf{J}$ Exp Biol, 2002. 205(Pt 14): p. 1979-86.

31. Lu, C., et al., Intracrine hepatopoietin potentiates AP-1 activity through JAB1 independent of MAPK pathway. FASEB J, 2002. 16(1): p. 90-2.

32. Wang, Y., et al., Hepatopoietin interacts directly with COP9 signalosome and regulates AP-1 activity. FEBS Lett, 2004. 572(1-3): p. 85-91.

33. Wang, G., et al., Identification and characterization of receptor for mammalian hepatopoietin that is homologous to yeast ERV1. J Biol Chem, 1999. 274(17): p. 11469-72.

34. Gandhi, C.R., et al., A fresh look at augmenter of liver regeneration in rats. Hepatology, 1999. 29(5): p. 1435-45.

35. Li, Y., et al., Stimulation of the mitogen-activated protein kinase cascade and tyrosine phosphorylation of the epidermal growth factor receptor by hepatopoietin. J Biol Chem, 2000. 275(48): p. 37443-7.

36. Francavilla, A., et al., Augmenter of liver regeneration: its place in the universe of hepatic growth factors. Hepatology, 1994. 20(3): p. 747-57.

37. Polimeno, L., et al., Molecular mechanisms of augmenter of liver regeneration as immunoregulator: its effect on interferon-gamma expression in rat liver. Dig Liver Dis, 2000. 32(3): p. 217-25.

38. Chen, X., et al., The potentiation role of hepatopoietin on activator protein1 is dependent on its sulfhydryl oxidase activity. J Biol Chem, 2003. 278(49): p. 49022-30. 


\section{Chapter 2}

\section{PURIFICATION AND CHARACTERIZATION OF AUGMENTER OF LIVER REGENERATION}

This unusual diversity of proposed functions for ALR makes it the most enigmatic of those sulfhydryl oxidases, which show homology with QSOX. Here, we build upon the ALR/ERV1p family with a further characterization of human ALR. Our work on the fundamental redox behavior of ALR has also uncovered an intriguing new activity of ALR of possible relevance to some of its physiological functions.

\subsection{Experimental Procedures}

\subsubsection{Materials}

A pT7T3D plasmid containing the short-form ALR sequence was obtained through the I.M.A.G.E. Consortium. The plasmid was amplified in Top10 E. coli cells and harvested using a Qiaprep Spin miniprep kit. For cloning, the long Histagged linker, the sense primer 5'-CTGGAATTCATGCGGACGCA- 3' was used to incorporate an EcoR I restriction site at the 5' end of the ALR sequence. For the short linker His-tagged enzyme, the sense primer 5'CTGGCTAGCATGCGGACGCA-3' introduced an Nhe I restriction site. In both cases, the antisense primer 5'-CTGAAGCTTCTAGTCACAGG-3' encoded a Hind III restriction site at the 3' end of the ALR sequence. PCR products were purified using a Qiagen PCR purification kit and digested with appropriate restriction enzymes at $37{ }^{\circ} \mathrm{C}$. PTrcHis (Invitrogen) was digested with the same restriction 
enzymes. The DNA was ethanol precipitated, redissolved in buffer and ligated overnight with $\mathrm{T} 4$ Ligase at $4{ }^{\circ} \mathrm{C}$. The plasmid was ethanol precipitated, suspended in water and used to transform BL21(DE3) chemically competent cells (Invitrogen). Several colonies were picked for sequencing. Glycerol stocks were made and stored at $-80^{\circ} \mathrm{C}$.

\subsubsection{General}

Unless otherwise stated, all buffers were $50 \mathrm{mM}$ potassium phosphate, $\mathrm{pH}$ 7.5, containing $0.3 \mathrm{mM}$ EDTA. Visible and ultraviolet spectra were recorded on Hewlett-Packard $8452 \mathrm{~A}$ or 8453 diode array spectrophotometers. Concentrations of ALR were expressed using a molar extinction coefficient of $11.6 \mathrm{mM}^{-1} \mathrm{~cm}^{-1}$ at 456 $\mathrm{nm}$ for the enzyme-bound flavin determined upon release of free FAD with $0.5 \mathrm{mM}$ cetyltrimethylammonium bromide (CTAB). Anaerobic methods were as described previously [1]. ALR was photoreduced anaerobically $4 \mathrm{~cm}$ from a 150 -watt flood lamp using $1.0 \mu \mathrm{M}$ 5-deazaflavin and $1 \mathrm{mM}$ EDTA in phosphate buffer. All stoichiometries reported are on a per flavin (per subunit) basis. Gel filtration was performed at a flow rate of $1.0 \mathrm{~mL} / \mathrm{min}$ on a Superdex $200 \mathrm{HR}$ 10/30 column from Pharmacia using an Äkta FPLC. A homology model of human ALR was constructed using Swiss-PDB viewer with the rat ALR coordinates (1OQC). Structures were visualized with DS ViewerPro (Accelerys).

\subsubsection{Determination of Midpoint Potentials}

Solutions of $15 \mu \mathrm{M}$ of the C74-85 double mutant short-form ALR in $0.8 \mathrm{~mL}$ of phosphate buffer containing $2 \mu \mathrm{M}$ methyl viologen were deoxygenated in dim light in the presence of $15 \mu \mathrm{M}$ of one of the following redox dyes: indigo disulfonate (-121 mV), anthraquinone-2,6-disulfonate (-184 mV), anthraquinone-2- 
sulfonate $(-226 \mathrm{mV})$, or phenosafranine $(-252 \mathrm{mV})$. After an initial spectrum was recorded, the mixture was progressively reduced by the addition of aliquots of dithionite. Subsequent spectra were recorded after redox equilibration (typically $<6$ min) and stored for analysis. Anthraquinone-2,6-disulfonate had a redox potential which closely matched the short-form ALR. Here, the 2-electron reduction of ALR was followed at $456 \mathrm{~nm}$ and the dye at $341 \mathrm{~nm}$. The resulting linear plots of log [oxidized]/[reduced] enzyme versus log [oxidized]/[reduced] dye yielded a midpoint potential for ALR of $-178 \pm 2 \mathrm{mV}$ (four determinations).

\subsubsection{Enzyme Assays}

ALR was assayed in a Clarke-type oxygen electrode (YSI 5331) and oxygen monitor (YSI 5300) in $2 \mathrm{~mL}$ of air-saturated $50 \mathrm{mM}$ potassium phosphate (pH 7.5, $0.3 \mathrm{mM}$ EDTA, $25^{\circ} \mathrm{C}$ ). A background trace followed the non-enzymatic oxidation of thiol before the addition of enzyme. Thiol substrates were prepared freshly in distilled water and were standardized using DTNB.

\subsubsection{Protein Expression}

Starter cultures $(5 \mathrm{~mL}$ in Luria-Bertani media containing $50 \mu \mathrm{g}$ ampicillin/mL) were grown overnight at $37^{\circ} \mathrm{C}$ and used to inoculate each of four 2 L flasks containing $500 \mathrm{~mL}$ of the same media supplemented with $5 \mu \mathrm{M}$ riboflavin. When the absorbance at $600 \mathrm{~nm}$ reached 0.6 , the cells were induced with $1 \mathrm{mM}$

IPTG and incubated for an additional $5.5 \mathrm{~h}$ at $37^{\circ} \mathrm{C}$. Cells were harvested at $4000 \mathrm{~g}$ for $30 \mathrm{~min}$ at $4{ }^{\circ} \mathrm{C}$. 


\subsubsection{Preparation of Cellular Extract}

Cells $(10 \mathrm{~g})$ were resuspended in $25 \mathrm{~mL}$ of $50 \mathrm{mM}$ potassium phosphate buffer, $\mathrm{pH} 7.5$, containing $300 \mathrm{mM} \mathrm{NaCl}, 0.1 \mathrm{mg} / \mathrm{mL}$ lysozyme, and general-use protease inhibitor cocktail (Sigma). The cells were disrupted with two passes through a French Press at 10,000 psi. After brief sonication to shear DNA, the cell lysate was centrifuged at $6000 \mathrm{~g}$ for $30 \mathrm{~min}$.

\subsubsection{Refolding of Long Peptide Linker ALR}

ALR with the long peptide linker forms inclusion bodies. After centrifugation, the cell debris was resuspended in $25 \mathrm{~mL}$ of $50 \mathrm{mM}$ phosphate buffer, $\mathrm{pH} 7.5$, without EDTA but containing $8 \mathrm{M}$ urea, $10 \mathrm{mM}$ DTT and $2 \mathrm{mM}$ FAD. The resulting suspension was dialyzed for a total of $22 \mathrm{~h}$ against two changes of the same buffer without additions and then centrifuged at $6000 \mathrm{~g}$.

\subsubsection{Purification of ALR}

The crude cell extract, or the reconstituted inclusion body dialyzate, were made $10 \mathrm{mM}$ in $\beta$-mercaptoethanol and mixed with Invitrogen probond resin $(1 \mathrm{~mL}$ of resin for every $8 \mathrm{~mL}$ of solution). After mixing end-over-end for $1 \mathrm{~h}$ at $4{ }^{\circ} \mathrm{C}$, the resin was loaded into a column and washed with $4 \mathrm{~mL}$ aliquots of the following solutions: three washes of $50 \mathrm{mM}$ phosphate containing $300 \mathrm{mM} \mathrm{NaCl}, 10 \mathrm{mM} \beta$ mercaptoethanol, $10 \mathrm{mM}$ imidazole, $\mathrm{pH}$ 7.5; three of the same solution without $\mathrm{NaCl}$; and one wash omitting $\beta$-mercaptoethanol. The column was then developed with single $5 \mathrm{~mL}$ aliquots of phosphate buffer without salt or $\beta$-mercaptoethanol containing 50, 200 and $500 \mathrm{mM}$ imidazole. ALR elutes as a bright yellow band in $200 \mathrm{mM}$ imidazole and was immediately desalted using PD-10 columns equilibrated with $50 \mathrm{mM}$ phosphate buffer, $\mathrm{pH} 7.5$, containing $0.3 \mathrm{mM}$ EDTA. 
ALR was stored routinely at $4{ }^{\circ} \mathrm{C}$. To ensure maximal flavin loading, ALR was incubated before use at $4{ }^{\circ} \mathrm{C}$ in anaerobic buffer containing $5 \mathrm{mM}$ DTT and an equimolar concentration of free FAD. After at least one hour, excess unbound FAD was removed by gel filtration on a PD10 column equilibrated with aerobic phosphate buffer. During gel filtration the blue semiquinone form of ALR rapidly reverts to the bright yellow color of the oxidized protein.

\subsubsection{Mutation Studies of ALR}

Cysteine to alanine mutations used Quickchange Directed Mutagenesis (Stratagene). The primers (Integrated DNA Technologies) were as follows:

C15A: 5'-GTTTAGGGAGGACGCCCCGCCGGATCGCG-3' and 5'-CGCGATCCGGCGGGGCGTCCTCCCTAAAC-3'; C124A: 5'-GGAAGGATGGCTCCGCTGACTAGAAGCTTGGC-3' and 5'-GCCAAGCTTCTAGTCAGCGGAGCCATCCTTCC-3'; C74A: 5'-CCTAAGAAAAAGGCTGGCCAGGAACCACCCAGAC-3' and 5'-GTCTGGGTGGTTCCTGGCCAGCCTTTTTCTTAGG-3'; C85A: 5'-CCCGCACCCGGGCAGCCTTCACACAGTGGC-3' and 5'-GCCACTGTGTGAAGGCTGCCCGGGTGCGGG-3'.

\subsubsection{Isolation of ALR Peptides}

ALR was alkylated at $25{ }^{\circ} \mathrm{C}$ in phosphate buffer containing $3 \mathrm{mM}$ iodoacetic acid following the thiol titer using DTNB. After $6 \mathrm{~h}$, excess iodoacetate was removed by washing the fully alkylated protein with $20 \mathrm{mM}$ ammonium bicarbonate in a Centricon 30. The protein solution was made $0.1 \%$ in SDS, boiled for $5 \mathrm{~min}$, and digested at $25{ }^{\circ} \mathrm{C}$ with $3 \% \mathrm{w} / \mathrm{w}$ trypsin. Peptides were separated using a Hewlett Packard series 1100 HPLC with a Phenomenex Jupiter C18 300A 
$250 \times 4.60 \mathrm{~mm}, 5$ micron column. Molecular weights were determined using a Maldi Omniflex NT and TOF MS ESI.

\subsubsection{Stopped-Flow Spectrophotometry}

Reactions were followed at $25^{\circ} \mathrm{C}$ in a Hi-Tech Scientific SF-61 SX2 double mixing stopped-flow system using software from Hi-Tech. Prior to anaerobic experiments, the driving syringes and flow cell were soaked for several hours with $10 \mathrm{mM}$ dithionite solution. Solutions of DTT were prepared in phosphate buffer and standardized with DTNB. Two-electron reduced ALR was prepared in a tonometer and mixed with aerobic solutions made by mixing appropriate volumes of anaerobic and oxygen saturated buffer [39]. Cytochrome $c$ turnover experiments were performed in double-mixing mode in aerobic solutions. ALR (syringe A) was

first mixed with DTT (syringe B) and after $50 \mathrm{~ms}$ mixed with cytochrome $c$ (syringe C) and buffer or superoxide dismutase (syringe D) to give final concentrations of $2.5 \mu \mathrm{M}$ ALR, $2 \mathrm{mM}$ DTT, $0-50 \mu \mathrm{M}$ cytochrome and 0 or 10 unit $\mathrm{mL}$ superoxide dismutase in phosphate buffer, $25{ }^{\circ} \mathrm{C}$. Initial rates were determined and $\mathrm{k}_{\mathrm{cat}}$ and $\mathrm{K}_{\mathrm{m}}$ values estimated by non-linear regression.

\subsection{Results and Discussion}

\subsubsection{Construction Expression, and Purification of Human ALR.}

The majority of published work on ALR, including the recent crystal structure [2], has been performed with the short form of the protein which lacks an 80-residue extension at its N-terminus. For our initial characterization of the redox behavior of ALR, we have chosen this form because it can be readily expressed heterologously in E. coli [3] and it allows a ready comparison with earlier work. In 
these prior studies, HIS tags have been appended to either $\mathrm{N}$ - or C-termini of mammalian ALR [3]. We have largely used an N-terminal tag MGGSHHHHHHGMAS identical to that chosen for crystallization trials of the rat ALR protein [4]. However, some preliminary experiments were conducted with a longer N-terminal linker (see Materials and Methods). To date, we have observed no significant differences in catalytic or redox behavior between the two tagged forms. The shorter construct typically gave $25-30 \mathrm{mg}$ of $>95 \%$ purified protein/L of

medium. Approximately $85 \%$ of the protein induced by IPTG was found to be soluble under the growth conditions used (see Methods). In contrast, the longer linker ALR construct formed inclusion bodies in E. coli and was refolded and reconstituted with flavin before purification as described in Methods. It proved very prone to re-aggregation and was only used in initial experiments.

\subsubsection{Preliminary Characterization of Human ALR}

Figure 2 shows a UV/VIS spectrum of the short-linker recombinant enzyme. The spectrum is weakly resolved in the flavin region with peaks at 456 and 376, somewhat different from the 450 and $360 \mathrm{~nm}$ reported earlier for rat shortform ALR [3]. The molar extinction coefficient for the bound FAD moiety in human ALR was experimentally determined to be $11,600 \pm 100 \mathrm{M}^{-1} \mathrm{~cm}^{-1}$ at $456 \mathrm{~nm}$ after the addition of $0.5 \mathrm{mM} \mathrm{CTAB}$ (see Methods). This value is significantly larger than a previously assumed value of $10,000 \mathrm{M}^{-1} \mathrm{~cm}^{-1}$ [5]. Release of flavin, judged by the reversion to a spectrum of free FAD, was complete in less than $20 \mathrm{~s}$ (not shown). The $280 \mathrm{~nm} / 450 \mathrm{~nm}$ absorbance ratio of freshly prepared ALR was 4.8 (Figure 2). Human ALR shows negligible flavin fluorescence, amounting to less than $0.5 \%$ of an equivalent concentration of free FAD excited at $450 \mathrm{~nm}$ and 
emitting at $530 \mathrm{~nm}$ (not shown; see Methods). As expected, ALR shows a typical protein fluorescence exciting at $280 \mathrm{~nm}$ and emitting at $340 \mathrm{~nm}$ (not shown).

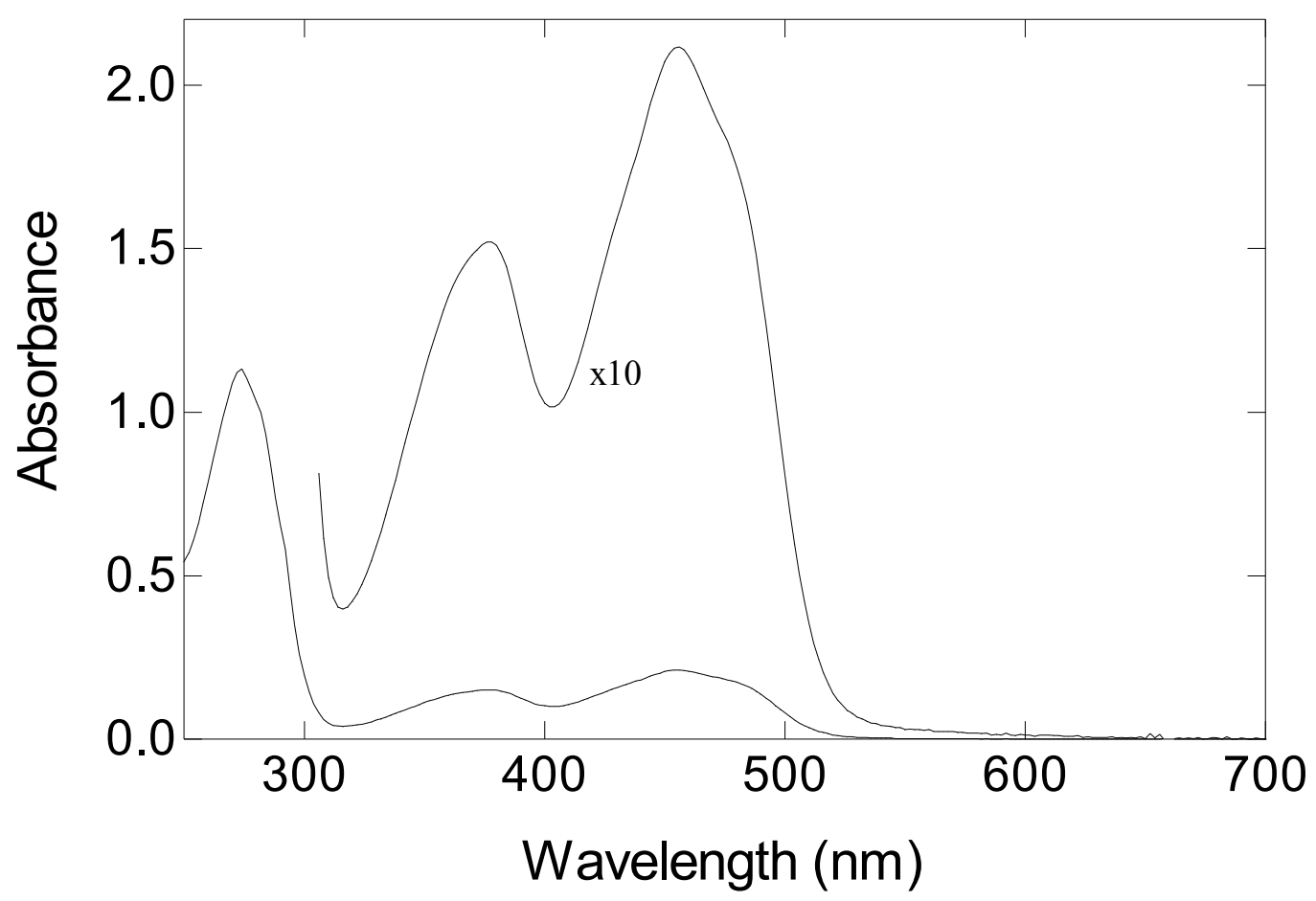

Figure 2.1: UV/VIS spectrum of recombinant human ALR. To maximize flavin content and minimize turbidity ALR was incubated anaerobically for $1 \mathrm{~h}$ at $4{ }^{\circ} \mathrm{C}$ in $50 \mathrm{mM}$ phosphate buffer, $\mathrm{pH} 7.5,25^{\circ} \mathrm{C}$ containing 0.3 $\mathrm{mM}$ EDTA, $5 \mathrm{mM}$ DTT and $100 \mu \mathrm{M}$ FAD. The mixture was then gel-filtered and the spectrum of ALR measured immediately at $25^{\circ} \mathrm{C}$. The upper curve is amplified 10-fold to show details of the flavin spectrum. 
Our short-linker human protein is prone to slowly increasing turbidity upon storage under aerobic conditions. This does not reflect global denaturation, because the precipitate is bright yellow and none of the non-covalently bound flavin is released into solution (see later). Precipitation can be largely avoided by storing the protein under nitrogen and it can be reversed after incubation with excess DTT. Figure 2.1 was recorded immediately after DTT pretreatment and gel filtration (see Methods). An alternate strategy to avoid aggregation is described later.

\subsubsection{Homology Model and Disulfide Connectivity in Human ALR}

Since human and rat ALR show about $86 \%$ sequence identity, a threaded minimized estimate of the structure of the dimeric human protein based on the rat structure [1] can be obtained with considerable confidence. This model (focusing on the blue subunit in Figure 2.2) shows that the conserved redox-active disulfide C62-65 is primed for communication with the flavin ring with the sulfur of C65 (orange) at a distance of 3.2 Angstroms from the C-4a position of the isoalloxazine ring. A second disulfide (C91-108) is conserved in ERV1p, ERV2p and mammalian ALR (Figure 1.1) and forms an apparent structural disulfide bond between a helix and a strand in the crystal structure of ERV2p [6] and ALR [5] (Figure 2.2). The third disulfide bond forms intersubunit links (C15-124; [5]) between the flexible $\mathrm{N}$ and C-terminii of the ALR structure (Figure 2.2). These two intersubunit disulfides (out of a total of six disulfide bridges in the dimer) are unique to ALR: they are not found in either its yeast homolog, ERV1p, or the ERresident yeast protein ERV2p. Unlike the rat and mouse enzymes, each subunit of human ALR contains two additional non-conserved free cysteines residues (C74 and C85) depicted at the top left of Figure 2.2 and, schematically, in Figure 2.3A. 


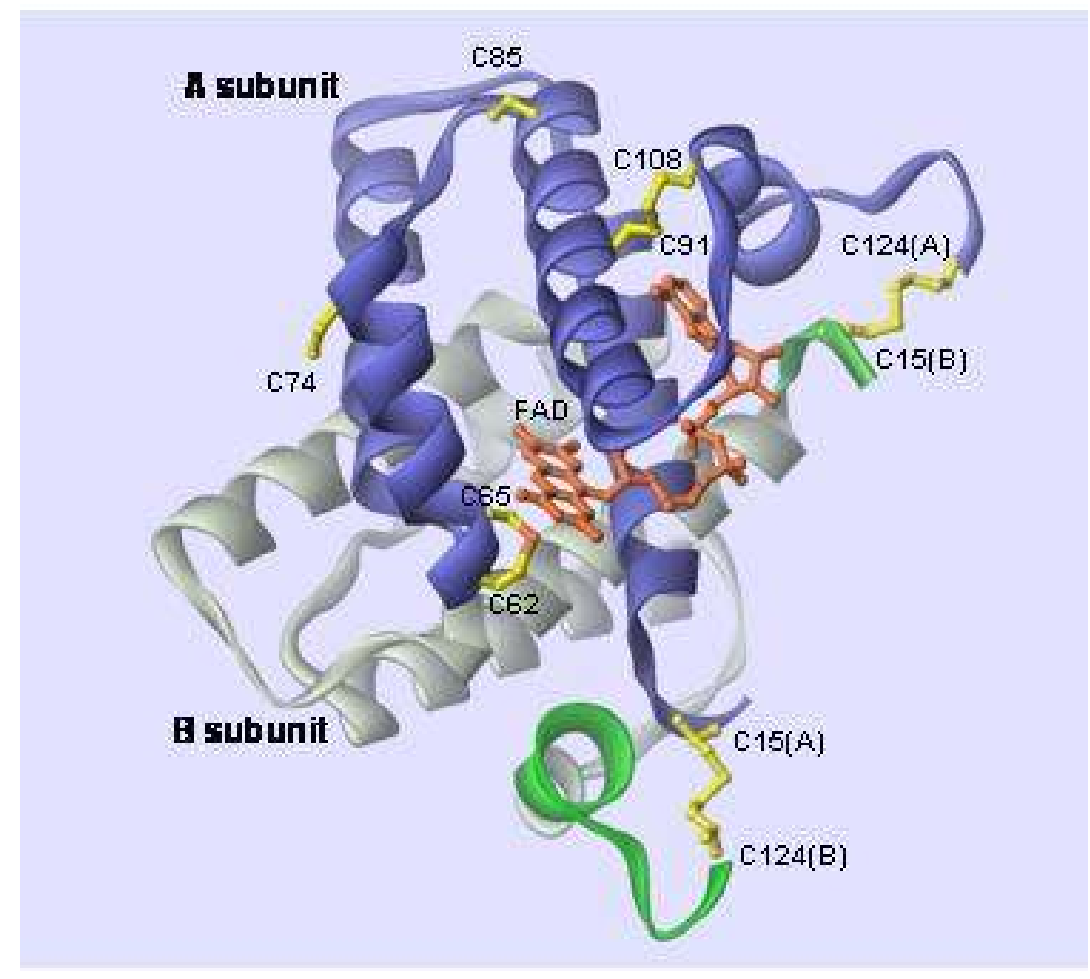

Figure 2.2: Homology model of human short-form ALR based on the crystal structure of rat ALR. The model was constructed using Swiss PDB viewer and the coordinates viewed by DS ViewerPro. Subunit A is shown in blue and subunit $\mathrm{B}$ in grey (with $\mathrm{N}$ and $\mathrm{C}$ termini in green) Cysteine and half-cystine residues are numbered and shown in yellow. The FAD is orange, as is the sulfur atom of C65 which likely participates in $\mathrm{C} 4 \mathrm{a}$-adduct formation with the flavin. In subunit $\mathrm{B}$ the FAD is omitted and only C15(B) and C124(B) are depicted. 


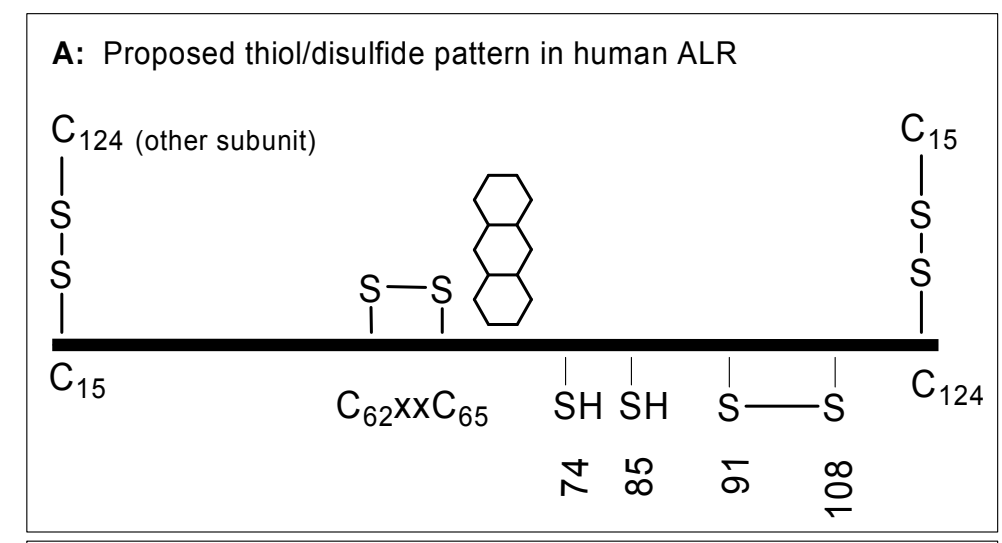

B: Pattern advocated by Chen et al.

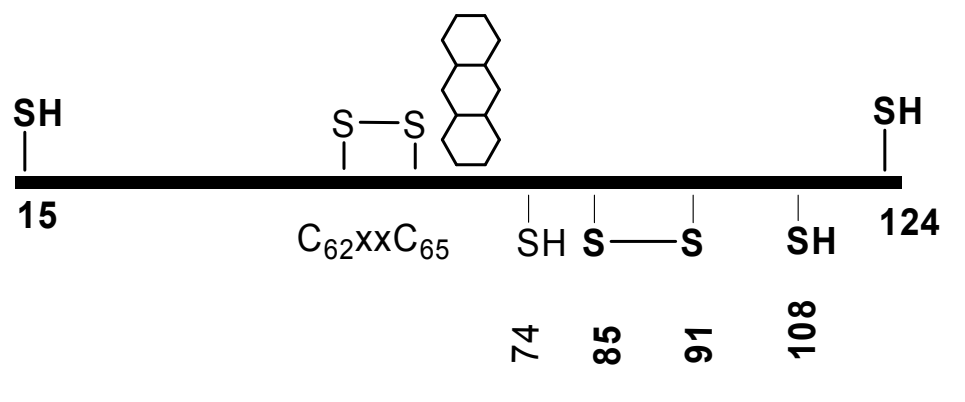

Figure 2.3: Cysteine residues and disulfide connectivity of human ALR. Panel A represents the pattern inferred from the crystal structure of rat ALR. Panel B is that proposed by Chen et al. [7]. The flavin ring is shown schematically next to the proximal disulfide C62-65.

A recent paper [7] proposed a pattern of disulfide bond connectivity in human short-form ALR that conflicts with that reported in the crystal structure of its rat counterpart [5]. This alternative connectivity (panel B, Figure 2.3) was deduced from the mass of proteolytic peptides derived from ALR that was not alkylated prior to digestion. Unfortunately, confounding disulfide exchange reactions can readily occur in the presence of free thiols during denaturation and prolonged digestion. Notwithstanding this technical issue, the new proposed 
disulfide pattern seems highly unlikely a priori. First, a C85-91 disulfide bond could only apply to human ALR because the counterpart of C85 is not found in any other ALR sequenced to date. (For example, Figure 1.1 shows that this cysteine is replaced by a serine in rat ALR). Second, the rearranged pattern would remove the conserved structural disulfide C91-108 in ERV/ALR family members (Figure 1.1) and replace it with C85-91. Third, the homology model in Figure 2.2 shows that the proposed C85-91 disulfide could not be accommodated within the alpha-helix that runs from residues 82-101 in ALR.

Experimental evidence is also inconsistent with the model in Figure 2.3B. Figure 2.3A predicts a free thiol titer of 2 per subunit $(\mathrm{C} 74, \mathrm{C} 85)$, whereas panel $\mathrm{B}$ implies a total of 4 reduced cysteine residues $(\mathrm{C} 15, \mathrm{C} 74, \mathrm{C} 108, \mathrm{C} 124)$. The reaction between $0.5 \mathrm{mM}$ DTNB and short linker human ALR is complete in less than $15 \mathrm{~s}$ at pH 7.5 and yields a stoichiometry of 2.0 free cysteines per monomer (see Methods). This rapidity suggests that both thiols are exposed to solvent; no further reaction occurs upon denaturation of ALR with either $0.5 \mathrm{mM}$ or $5 \mathrm{mM} \mathrm{CTAB}$ (not shown). The facile reaction of two thiols is consistent with the evident solvent accessibility of both C74 and C85 in Figure 3 (solvent accessible surface not shown). In accord with their non-conservation in ALR sequences (see earlier) the double mutant C74A/C85A gave fully active stable protein (see later). In addition, the double mutant showed essentially no reaction with DTNB $(<0.2$ reactive thiols per subunit; not shown) whereas the corresponding double mutant in Panel 2.3B would predict $\underline{4}$ free thiols/subunit.

Finally, panel B omits the interchain disulfide bridges (C15-124) clearly evident in the crystal structure of rat ALR [5] and reproduced in the homology model of the human protein in Figure 2.2. Mutation of either C15 or C124 in 
human ALR to alanine results in a fully active enzyme (Table 2.1) that shows essentially the same visible spectrum as wild-type ALR (see later). Like the wildtype protein, both mutant proteins run on gel filtration under native conditions as dimers (not shown; see Methods). Both single mutant proteins show an approximate unit increase in thiol titer (from 2 of wild-type to 3.0 and 3.1 per subunit for $\mathrm{C} 15 \mathrm{~A}$ and $\mathrm{C} 124 \mathrm{~A}$ respectively; see Methods). This data can only be accommodated if both $\mathrm{C} 15$ and $\mathrm{C} 124$ participate in disulfide bonds.

Table 2.1: DTT Oxidase Activity of Wild Type and Selected Cysteine Mutants of Human ALR

\begin{tabular}{|c|c|c|c|c|}
\hline ALR Construct & Linker & $\mathbf{k}_{\mathbf{c a t}}\left(\mathbf{m i n}^{-1}\right)$ & $\mathbf{K}_{\mathbf{m}}(\mathbf{m M})$ & $\mathbf{k}_{\mathbf{c a t}} / \mathbf{K}_{\mathbf{m}}\left(\mathbf{M}^{-1} \mathbf{s}^{-1}\right)$ \\
\hline Wild Type & Short & $66 \pm 6$ & $2.1 \pm 0.5$ & 520 \\
\hline C15A & Short & $52 \pm 2$ & $1.3 \pm 0.2$ & 670 \\
\hline C124A & Short & $54 \pm 2$ & $1.8 \pm 0.2$ & 500 \\
\hline C74A/C85A & Short & $50 \pm 3$ & $2.0 \pm 0.3$ & 420 \\
\hline C15A/C124A & Long & $57 \pm 3$ & $2.0 \pm 0.3$ & 475 \\
\hline C15A/C74A/C85A/C124A & Long & $75 \pm 3$ & $1.7 \pm 0.2$ & 735 \\
\hline
\end{tabular}


Further, evidence supporting interchain bridges comes from SDS-PAGE of the protein constructs as described in Figure 2.4. Like a human ALR-GFP fusion reported by Lisowsky and colleagues [3], wild type human ALR is a dimer in the absence of 2-mercaptoethanol, but a monomer in its presence (lanes 3 and 2, Figure 2.4, respectively). However both $\mathrm{C} 15 \mathrm{~A}$ and $\mathrm{C} 124 \mathrm{~A}$ mutants run as monomers in the presence or absence of reductant (lanes 6-9, Figure 2.4). In summary, the structural and biochemical evidence described above contradicts the model suggested by Chen et al. [7] and is completely consistent with the connectivity shown in panel A of Figure 2.3.

Finally, a general comment about the disulfide bonds in ALR is relevant here. It is unusual that an intracellular, but non-ER resident, eukaryotic protein contains structural disulfide bonds. The short form of ALR has apparently four per dimer. Surveys of disulfide bonds in proteins show that they are typically buried $(>70 \%$ of them are solvent inaccessible) $[8,9]$. However a number of the disulfides of ALR appear solvent accessible (using a $1.4 \AA$ probe radius; not shown) and it will be interesting to learn their redox state within the mitochondrial intermembrane space (see later). 


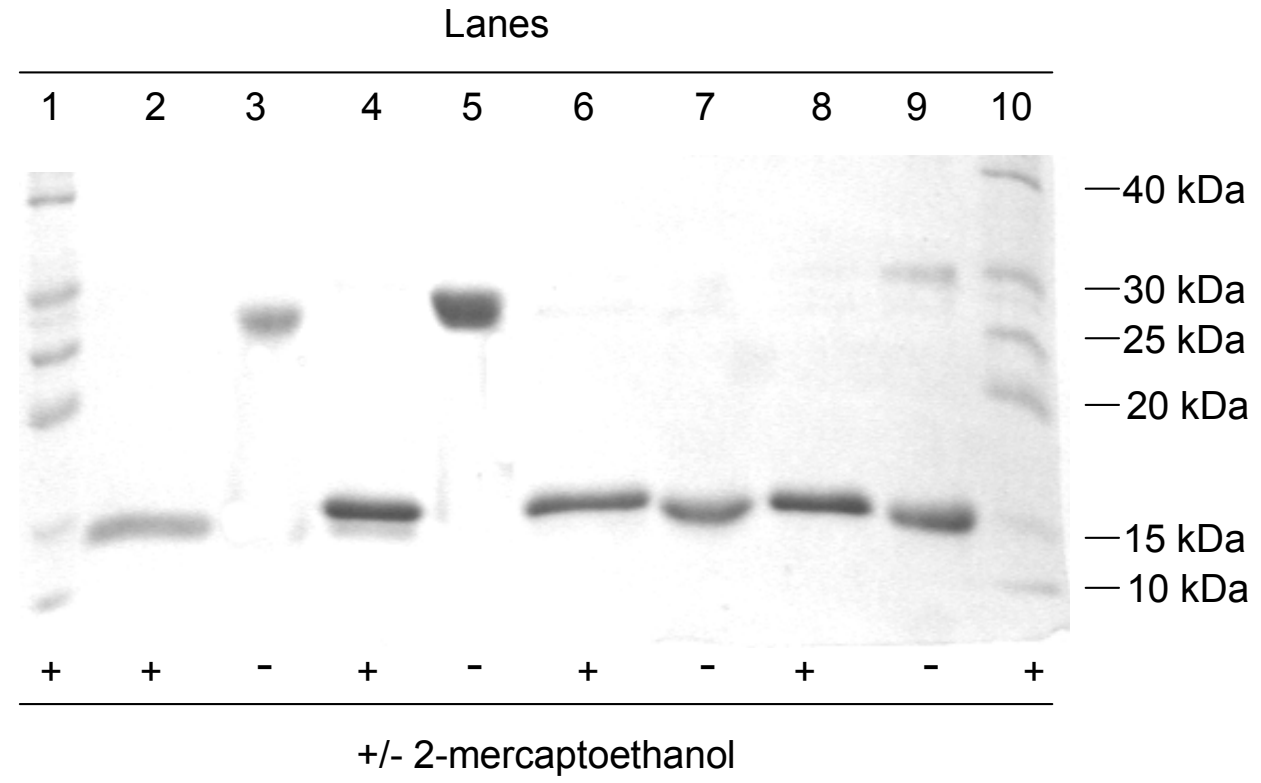

Figure 2.4: SDS-PAGE of recombinant wild-type ALR and selected cysteine to alanine mutants. Samples were run using an 18\% crosslinked gel. All of the ALR samples ran in the $10-40 \mathrm{kDa}$ region of the gel shown here. Lanes 1 and 10 were markers. ALR samples in even-numbered lanes from 2-9 were pre-reduced with 2-mercaptoethanol. Lanes 2 and 3; wild-type ALR; lanes 4 and 5; C74A/C85A double mutant; lanes 6 and 7: C15A ALR; lanes 8 and 9: C124A ALR. The faint dimer formation in lane 9 may reflect a small amount of disulfide crosslinking after SDS denaturation in the absence of 2mercaptoethanol. 


\subsubsection{DTT Oxidase Activity of the Thiol Mutant of ALR}

Identification of the physiological substrate(s) for ALR represents an important unresolved issue (see later). In prior work, human ALR showed a turnover number of about 4 disulfides generated/min using reduced lysozyme in 2 M urea [10]. We have used DTT here because it gives turnover numbers in the 50$75 /$ min range, is a convenient substrate, and provides a number of interesting insights into ALR catalysis. Table 2.1 shows that neither $\mathrm{k}_{\text {cat }}$ nor $\mathrm{K}_{\mathrm{m}}$ for DTT oxidation show large differences between wild type and single, double or quadruple cysteine mutant proteins. All of these constructs retain the active site $\mathrm{CxxC}$ motif. Lisowsky and colleagues [3], Chen et al. [7] and $\mathrm{Wu}$ et al. [5] have prepared both these active site mutants and report that they show undetectable sulfhydryl oxidase activity. Accordingly they have not been pursued here.

Two of the constructs in Table 2.1 have the longer N-terminal His-tag (see above) but this makes little difference to DTT oxidase activity. Clearly the free cysteines 74 and 85 are not essential for enzymatic activity towards DTT, consistent with their lack of conservation between rat and human sequences and their distance from the isoalloxazine ring (Figures 1.1 and 2.2). More significantly, the interchain disulfide CYS15-124 (Figure 2.2) is also not catalytically essential for the DTT oxidase activity measured here. Evidently this disulfide bond does not serve in a chain of disulfide bridges by relaying reducing equivalents to the proximal disulfide (C62-C65) in the way that the mobile CxC motif does in ERV2p [6].

\subsubsection{Rationale for Using the C74A/C85A Double Mutant of Human ALR}

As mentioned earlier, C74 and C85 in human ALR are not conserved in other ALRs and can both be mutated to alanine residues without significant impact 
on DTT oxidase activity. These two free surface-reactive cysteines cause slow aggregation of human short-form ALR under aerobic conditions. Thus the thiol titer drops from 2/subunit to 1.1 over one day in aerobic buffer $(\mathrm{pH} 7.5,0.3 \mathrm{mM}$ EDTA, $4{ }^{\circ} \mathrm{C}$ ) and progressive aggregation is evident from both gel filtration, SDSPAGE under non-reducing conditions, and light scattering experiments (not shown). While we can reverse this tendency of human ALR to self-oxidize using DTT, or minimize the effect with storage under nitrogen, it proved more convenient to perform subsequent studies with the $\mathrm{C} 74 \mathrm{~A} / \mathrm{C} 85 \mathrm{~A}$ double-mutant (see Methods).

\subsubsection{Dithionite Titrations of ALR}

Figure 2.5 shows a dithionite titration of human short-form double mutant ALR at $\mathrm{pH} 7.5$ in the presence of methylviologen to mediate transfer of reducing equivalents between reductant and the various redox forms of the protein. Complete reduction of the flavin requires about 2.3 electron equivalents of dithionite (see inset) with the clear intermediacy of significant levels of the blue neutral semiquinone. Assuming that the fully-formed neutral semiquinone of ALR has an extinction coefficient of $4.4 \mathrm{mM}^{-1} \mathrm{~cm}^{-1}$ at $570 \mathrm{~nm}$ (see later) about $40 \%$ of the flavin accumulates in the blue radical at the mid-point of flavin reduction. The behavior of ALR is unusual, since flavoprotein oxidases would be expected to form the red anionic flavin semiquinone $[11,12]$. Comparable reductive titrations of ALR up to $\mathrm{pH} 9.0$ provide no significant evidence of red anionic semiquinone (not shown). After the addition of about 2.3 electrons, a stable methylviologen radical appears judged by a significant shoulder at $390 \mathrm{~nm}$ and new absorbance at $580 \mathrm{~nm}$ 
(not shown). Clearly only the flavin center of ALR and not, additionally, the proximal disulfide is reduced under these conditions.

The midpoint potential for human short-form double mutant ALR was established by repeating dithionite titrations in the presence of a range of redox dyes (see Material and Methods). Four independent experiments with anthraquinone-2,6-disulfonate $\left(\mathrm{E}_{\mathrm{m}}=-184 \mathrm{mV}\right)$ gave a midpoint potential of $-178 \pm$ $2 \mathrm{mV}$ for the 2-electron reduction of this form of ALR. The redox-active disulfide (C62-65, Figure 2.2) must clearly have a considerably more negative potential, since we have been unable to reduce this center during the reductive titrations of this study.

\subsubsection{Photochemical Reduction}

A similar picture emerges from catalytic photoreduction using deazaflavin (see Methods). First, the flavin of ALR was completely reduced (curve 1, Figure 2.6); further anaerobic illumination had no apparent effect on the visible spectrum of the enzyme (or the subsequent stoichiometry of oxidative titrations, not shown). The solution was then titrated with standardized anaerobic potassium ferricyanide. Reoxidation was complete upon the removal of 2-electrons per flavin (curve 8 and inset). At intermediate stages of the titration very similar level of blue flavin semiquinone are encountered to those seen in Figure 2.5. 


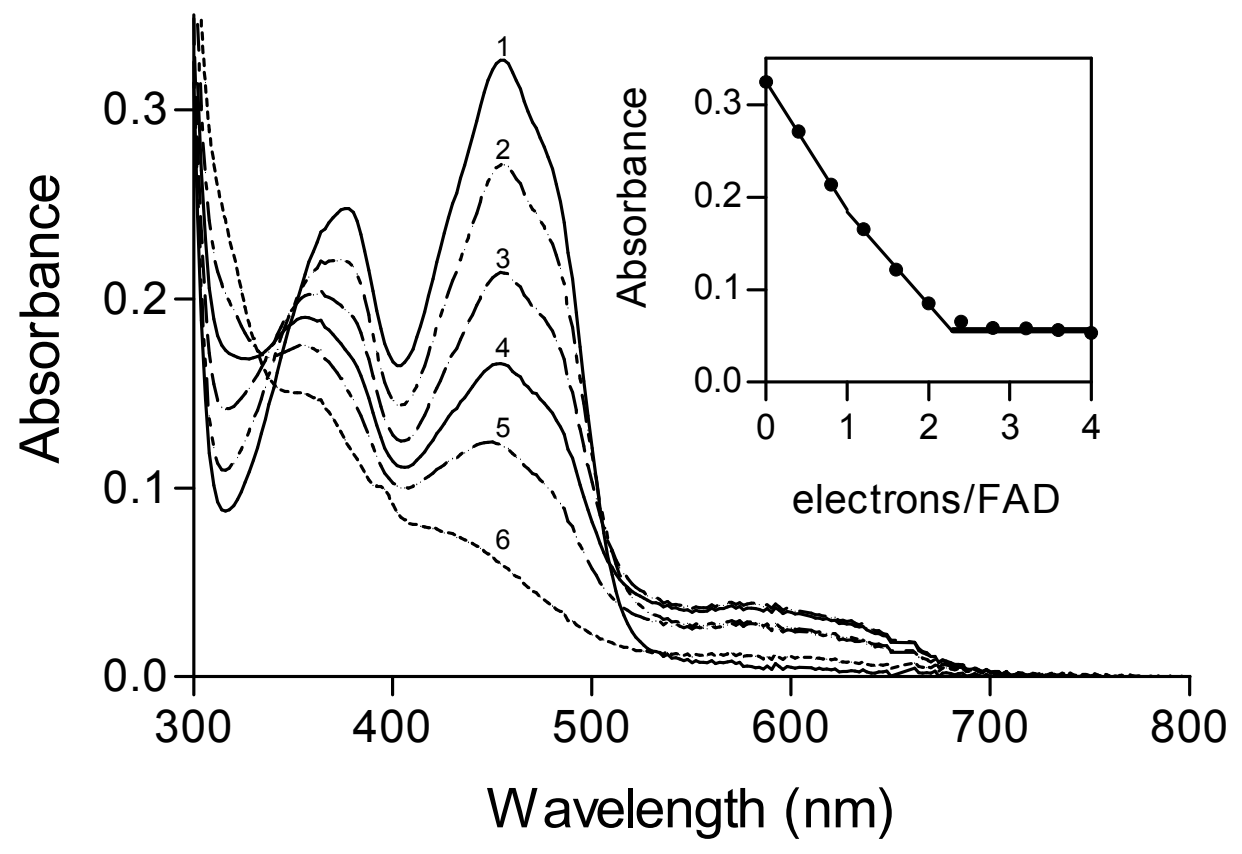

Figure 2.5: Dithionite titration of the C74A/C85A double-mutant of human ALR. The double mutant $(28 \mu \mathrm{M}$ in $50 \mathrm{mM}$ phosphate buffer, $\mathrm{pH}$ 7.5, containing $0.3 \mathrm{mM}$ EDTA and $1 \mu \mathrm{M}$ methylviologen) was made anaerobic (curve 1; see Methods) and titrated with $0.4,0.8,1.2,1.6$, and 2.8 electron equivalents of dithionite per subunit (curves 2-6 respectively). Intermediate spectra are omitted for clarity. The insert plots absorbance at $456 \mathrm{~nm}$ as the titration proceeds. 
As observed in Figure 2.5, the redox potentials of the flavin and of the proximal disulfide C62-65 appear widely separated, allowing essentially stoichiometric reduction of the flavin without significant accumulation of 4electron reduced protein. The long wavelength absorbance seen in Figures 2.5 and 2.6 has the fine structure expected for a blue neutral semiquinone radical (see later); the feature is clearly not that of a charge-transfer interaction between oxidized flavin and a proximal thiolate as observed with QSOX [1, 5, 13] or members of the pyridine nucleotide dependent disulfide oxidoreductases (reviewed in [14]).

\subsubsection{DTT Reduction under Anaerobic and Aerobic Turnover Conditions}

Figure 2.7 shows that one equivalent of DTT (2-electron equivalents per subunit; see inset) effects almost complete reduction of the flavin prosthetic group of human ALR. Unlike photochemical reduction (e.g. Figure 2.6, curve 1), significant levels of the blue radical persist even upon the addition of excess DTT (Figure 2.7, curve 7). However, much higher levels of the blue neutral semiquinone are observed during DTT turnover in aerobic buffer Figure 2.8. Here, oxidized ALR was mixed with $10 \mathrm{mM}$ DTT at $\mathrm{pH} 7.5$ and the spectral changes followed in the diode array spectrophotometer. The inset in Figure 2.8 shows that the blue semiquinone increases in a reaction that is half-complete about $19 \mathrm{sec}$ after the addition of DTT. At this $\mathrm{pH}$, bleaching at $456 \mathrm{~nm}$ largely precedes the appearance of the blue semiquinone. A somewhat smaller level of neutral radical was observed at $\mathrm{pH} 7.0$ by $\mathrm{Wu}$ et al. during their crystallographic investigations of the structure of recombinant rat ALR [5]. 


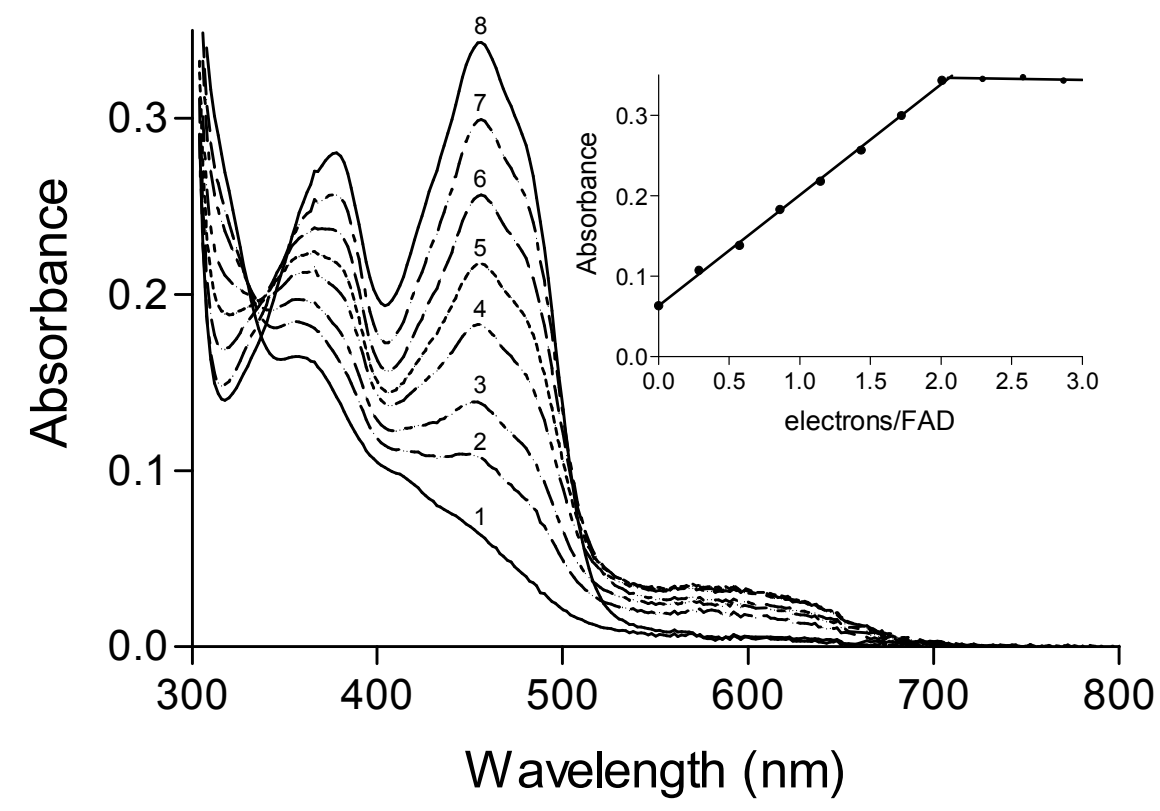

Figure 2.6: Reoxidation of photochemically reduced human ALR. Curve 1: an anaerobic solution of $30 \mu \mathrm{M}$ ALR was photoreduced with 5deazaflavin (for $25 \mathrm{~min}$; see Materials and Methods) and titrated with $0.29,0.57,0.86,1.15,1.43,1.72$, and 2.00 electron equivalents of ferricyanide (curves 2-8). The inset plots the absorbance changes at $456 \mathrm{~nm}$ against titrant added. 


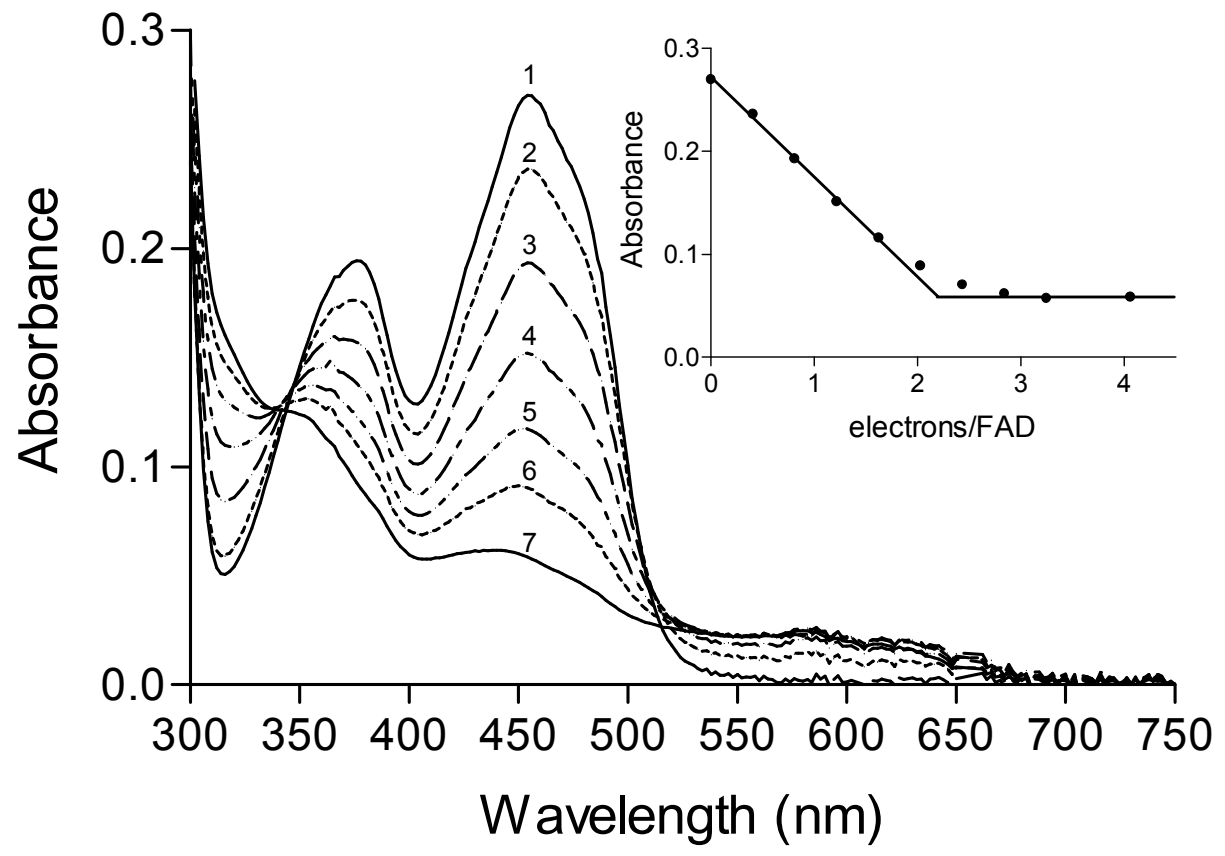

Figure 2.7: Anaerobic titration of ALR with DTT. Oxidized ALR (curve 1: $23 \mu \mathrm{M}$ in $50 \mathrm{mM}$ phosphate buffer, $\mathrm{pH} 7.5$, containing $0.3 \mathrm{mM}$ EDTA) was titrated anaerobically at $25^{\circ} \mathrm{C}$ with $0.4,0.8,1.2,1.6,2.0$, and 3.2 electron equivalents from DTT (curves 2-7, respectively). Intermediate spectra are omitted for clarity. The inset plots the absorbance change at $456 \mathrm{~nm}$ during the titration. 


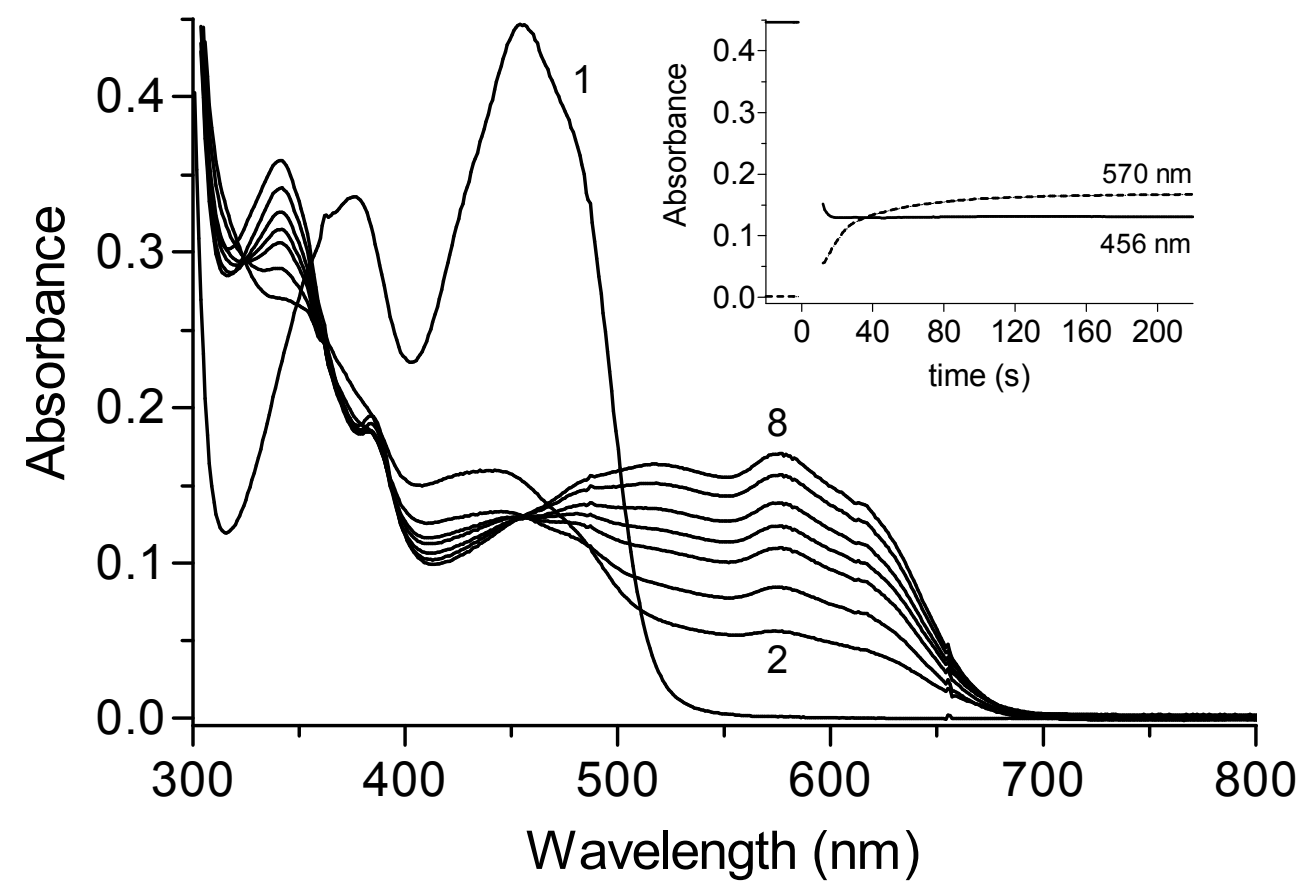

Figure 2.8: Enzyme-monitored turnover of DTT. ALR $(38.5 \mu \mathrm{M}$ in $0.8 \mathrm{~mL}$ of phosphate buffer, $\mathrm{pH} 7.5,25^{\circ} \mathrm{C}$ ) was mixed at time zero with $10 \mathrm{mM}$ DTT. Only selected spectra are shown for clarity. The inset plots absorbance change at $456 \mathrm{~nm}$ and $580 \mathrm{~nm}$. 
One explanation for the appearance of the radical upon the addition of a formal 2-electron reductant (DTT) is that it reflects a comproportionation reaction: either between two separate ALR dimers, or via electron transfer across subunits within the same dimer (depicted as 2.1 or 2.2 below):

$$
\mathrm{ALR}_{\text {dimer }} \cdot \mathrm{Fl}_{2 \mathrm{e}}+\mathrm{ALR}_{\text {dimer }} . \mathrm{Fl}_{\text {ox }} \leftrightarrow 2 \mathrm{ALR}_{\text {dimer }} . \mathrm{Fl} \bullet
$$

$$
\mathrm{ALR}_{\text {subunit A }} \cdot \mathrm{Fl}_{2 \mathrm{e}} / \mathrm{ALR}_{\text {subunit B }} \cdot \mathrm{Fl}_{\text {ox }} \leftrightarrow \mathrm{ALR}_{\text {subunit A. }} \mathrm{Fl} \bullet / \mathrm{ALR}_{\text {subunit B }} \cdot \mathrm{Fl} \bullet
$$

To assess the rate of the reaction 2.1, we mixed 2-electron reduced ALR (generated photochemically, see Methods) anaerobically with an equimolar concentration of oxidized ALR. Comproportionation equilibration yields the level of semiquinone seen in Figures 2.5 and 2.6 with a half-time of 6.6 min at $25{ }^{\circ} \mathrm{C}$ (not shown). This rate is too slow to account for the comparatively rapid appearance of blue semiquinone observed in the inset to Figure 2.8.

Dutton and colleagues have argued that electron transfer rates between redox centers are comparatively little influenced by the medium which separates them, but strongly influenced by driving force and edge to edge distance between reacting groups $[15,16]$. In dimeric ALR the closest distance between isoalloxazine rings $\mathrm{A}$ and $\mathrm{B}$ is about $19 \AA$ and this would correspond to an isopotential electron transfer rate of about $10 / \mathrm{sec}$ ([16]; this is roughly 10 -fold faster than catalytic turnover; Table 2.1). Even if this theoretical rate were overestimated by 100 -fold it 
would still be fast enough to account for the appearance of blue semiquinone in Figure 2.8. Thus comproportionation in ALR is likely dominated by electron tunneling across the dimer interface because of the relatively proximity of the two flavin rings.

\subsubsection{A New Enzymatic Activity for ALR}

We considered another possible explanation for the appearance of the flavin semiquinone in Figure 2.8: that it is the consequence of 1-electron reduction of dioxygen during turnover of DTT. The experiments described below show that this is not the case and have led to the discovery of a new enzymatic activity of ALR.

McCord and Fridovich and Massey et al. showed that a number of flavoproteins are weak de facto cytochrome $c$ reductases because they nonphysiologically leak traces of superoxide during aerobic turnover [17-19]. Two examples from this early work are particularly relevant because they are members of the pyridine nucleotide disulfide oxidoreductase family and contain flavin in close communication with a redox active disulfide [14]. The NADH-dependent cytochrome $c$ reductase activity of lipoamide dehydrogenase $(2.7 \mathrm{~mol}$ cytochrome $c$ reduced $/ \mathrm{min}$ ) was inhibited by $90 \%$ on the addition of superoxide dismutase (SOD). Similarly glutathione reductase catalyzes the NADPH dependent reduction of cytochrome $c(0.9 / \mathrm{min})$ and is $92 \%$ inhibited by SOD. The balance of noninhibitable cytochrome $c$ reductase activity (about 10\%) was also observed under rigorously anaerobic conditions.

In contrast to these flavoproteins, ALR-mediated aerobic reduction of cytochrome $c$ (Figure 2.9) is only slightly inhibited by a concentration of SOD that was shown in a separate experiment to completely inhibit the reduction of 
cytochrome in the xanthine/xanthine oxidase superoxide generating system (not shown; see Methods). Reduction of cytochrome $c$ by reduced ALR was followed in a double-mixing stopped-flow spectrophotometer to facilitate the measurement of initial rates (see Methods). The appreciable background contribution to these rates (shown by the dotted line in Figure 2.9) is the well-precedented non-enzymatic reduction of cytochrome $c$ by thiol compounds [20-22].

Consistent with this small effect of SOD, anaerobic assays (comparable to those shown in Figure 2.9) showed less than 10\% difference in rates with their aerobic counterparts (not shown). Using the Michaelis Menten equation to fit the SOD-independent heme reduction rates in the inset gives a $\mathrm{k}_{\text {cat }}$ of 270 cytochrome $c$ molecules reduced/min and a $\mathrm{K}_{\mathrm{m}}$ of $10 \mu \mathrm{M}$. To evaluate whether oxygen or cytochrome $c$ are better electron acceptors for ALR we needed to determine the $\mathrm{K}_{\mathrm{m}}$ for oxygen using the DTT concentration ( $2 \mathrm{mM})$ employed in Figure 2.9. Analysis of complete oxygen electrode traces from air saturation to zero oxygen concentration allowed rates to be estimated by drawing tangents to the curve for a range of oxygen concentrations [13]. The $\mathrm{K}_{\mathrm{m}}$ estimated from a Michaelis Menten plot of the data is about $240 \mu \mathrm{M}$ consistent with a marked slowing of the oxygen electrode trace as oxygen is depleted. Thus at least in vitro, oxygen appears to be a poorer substrate than cytochrome $c$ by about 100 -fold (with $\mathrm{k}_{\text {cat }} / \mathrm{K}_{\mathrm{m}}$ values of $4.2 \mathrm{x}$ 103 and $4.5 \times 105 \mathrm{M}^{-1} \mathrm{~s}^{-1}$ respectively). If this is the case, oxidized cytochrome $c$ would be expected to suppress the consumption of oxygen by ALR in the presence of DTT. Indeed, Figure 2.10 shows a significant delay in oxygen consumption (added to the approximate $6 \mathrm{~s}$ lag inherent in the sensor electrode). This lag persists until cytochrome $c$ is depleted (by direct reduction with ALR and non-enzymatic reduction with DTT as in Figure 2.9). 


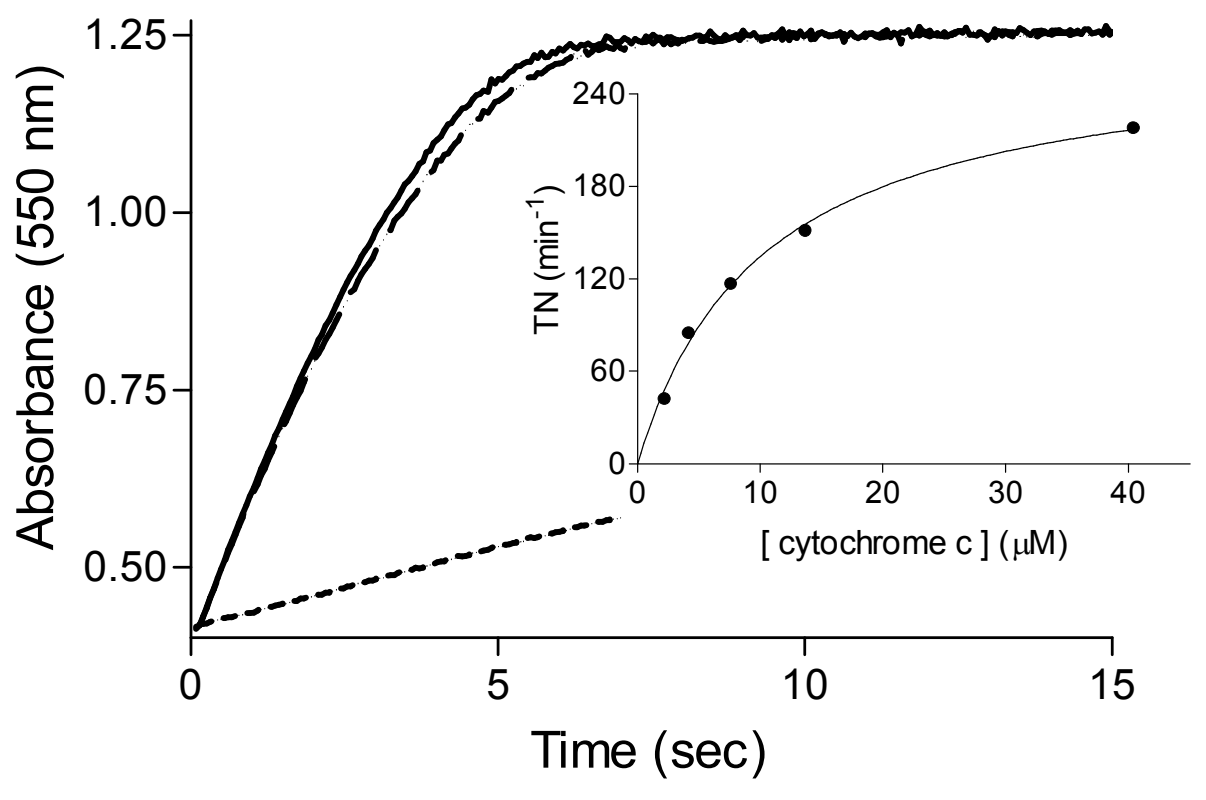

Figure 2.9: ALR-mediated reduction of cytochrome $c$. In a double-mixing experiment, cytochrome $c$ was first mixed with DTT and subsequently with ALR and/or SOD. The main panel plots the absorbance at $550 \mathrm{~nm}$ using $40 \mu \mathrm{M}$ cytochrome $c$ with $2.5 \mu \mathrm{M}$ ALR alone (solid line); with the additional presence of 10 units/mL SOD (long dashed line); or including SOD, but omitting ALR, to record the non-enzymatic reduction of cytochrome by DTT (short dashed line). Concentrations are those after double-mixing (throughout 2 $\mathrm{mM}$ DTT in $50 \mathrm{mM}$ phosphate buffer, $\mathrm{pH} 7.5,0.3 \mathrm{mM}$ EDTA at 25 ${ }^{\circ} \mathrm{C}$ ). Initial rates, corrected for non-enzymatic reduction, are plotted as a function of cytochrome concentration in the inset. The line is a fit to a $\mathrm{k}_{\text {cat }}$ of $270 / \mathrm{min}$ and a $\mathrm{K}_{\mathrm{m}}$ of $10 \mu \mathrm{M}$. 


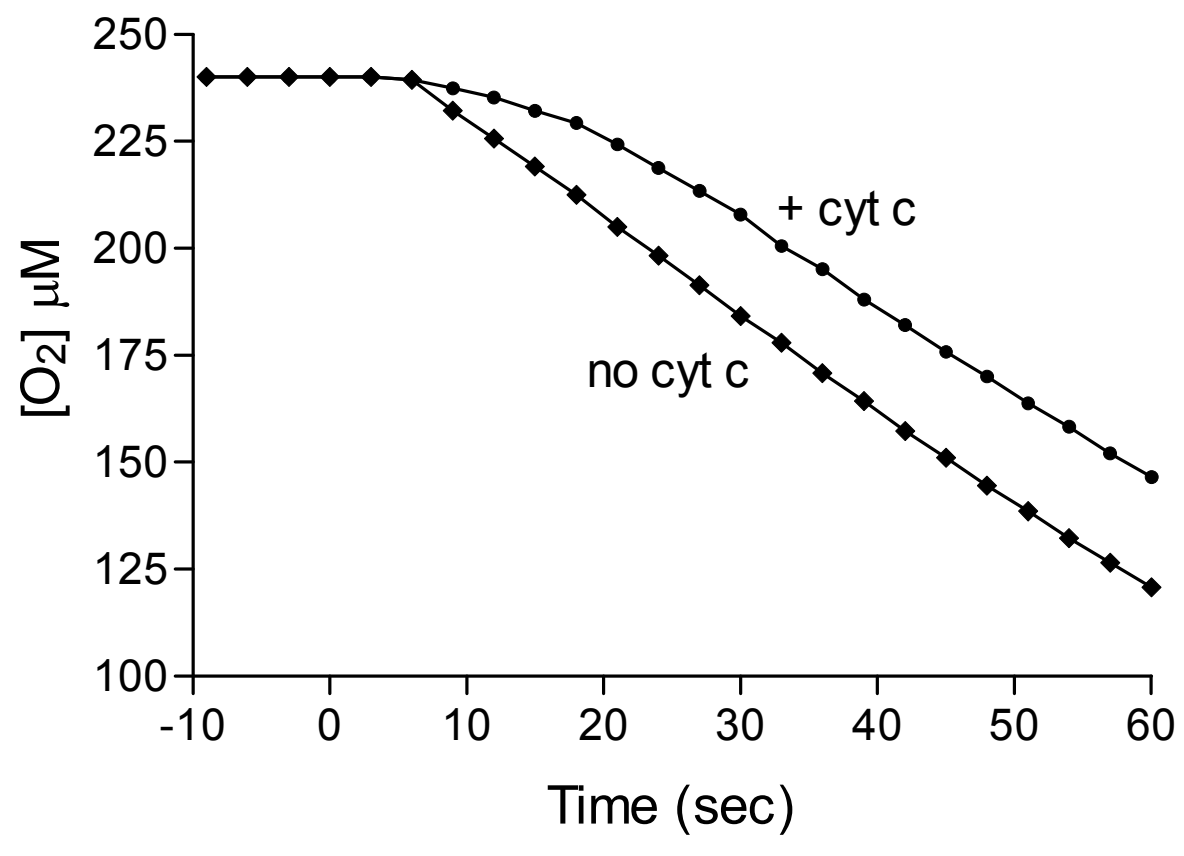

Figure 2.10: Cytochrome c inhibits oxygen consumption by ALR. Oxygen consumption was measured in the oxygen electrode after the addition of $2 \mu \mathrm{M}$ ALR at time zero to air saturated buffer containing $2 \mathrm{mM}$ DTT in the presence (circles) or absence (squares) of $100 \mu \mathrm{M}$ cytochrome $c$. The oxygen electrode has an intrinsic delay time of 6 seconds. 


\subsection{Conclusions}

This work presents the first detailed examination of the redox behavior of ALR and shows that only 2-reducing equivalents can be easily delivered to the short form of the human protein compared to the 4-electrons expected from the additional presence of the proximal disulfide (C62-65). Similarly, a proteolytic fragment of QSOX containing the ERV/ALR domain was also found to only undergo 2-electron reduction using either dithionite or the deazaflavin light method [23]. In both examples, the flavin is clearly the center with the most positive redox

potential. In neither case are thiolate to flavin charge-transfer complexes observed on 2-electron reduction. Instead, both ALR and the QSOX fragment yield the blue semiquinone during reductive titrations, although only traces are seen in the latter case [23].

Identification of the physiological substrates for mammalian ALR is an important ongoing exercise $[3,5,7,24]$. In addition to a proposed role in $\mathrm{Fe} / \mathrm{S}$ traffic [24], ALR might contribute in some way to the introduction of disulfides found in proteins residing in the intermembrane space: including thionein $[25,26]$, TIM10 [27], TIM13 [28] and superoxide dismutase [29]. In terms of electron acceptors for ALR, our work suggests that ALR may not necessarily function as a sulfhydryl oxidase in the mitochondrial intermembrane space. Thus, while cytochrome $c$ is often used as a non-physiological oxidant for flavoproteins in vitro, in the present case ALR is located in the same cellular compartment, as almost millimolar concentrations of cytochrome $c$ [30,31]. A significant amount of this cytochrome $c$ is "free" [32], and in its oxidized form [33]. This abundance of an apparently preferred substrate of ALR contrasts with the 2-10 $\mu \mathrm{M}$ levels of oxygen that prevail in the mitochondrion of respiring tissues [34]. Even at air saturation 
(240 $\mu \mathrm{M}$ oxygen), $100 \mu \mathrm{M}$ oxidized cytochrome $c$ strongly suppresses oxygen consumption by ALR (evident from the initial lag in Figure 2.10).

In sum, these data suggest that cytochrome $c$ should be considered as a potential oxidant for ALR in vivo. In this mode ALR-mediated oxidations could then be coupled to the respiratory chain without the generation of hydrogen peroxide observed in the oxidase reaction. Further work will examine the long form of human ALR to see whether the additional N-terminal CxxC motif modulates the redox behavior and catalytic versatility of this interesting flavoenzyme. 


\section{REFERENCES}

1. Hoober, K.L., et al., A sulfhydryl oxidase from chicken egg white. J Biol Chem, 1996. 271(48): p. 30510-6.

2. Hoober, K.L., et al., Sulfhydryl oxidase from egg white. A facile catalyst for disulfide bond formation in proteins and peptides. J Biol Chem, 1999. 274(32): p. 22147-50.

3. Lisowsky, T., et al., Mammalian augmenter of liver regeneration protein is a sulfhydryl oxidase. Dig Liver Dis, 2001. 33(2): p. 173-80.

4. Wu, C.K., Dailey, T.A., Dailey, H. A., Francavilla, A., Starzl, T. E., Wang, B. C., and Rose, J. P., Expression, purification, crystallization and preliminary $x$-ray analysis of the augmenter of liver regeneration. Protein and Peptide Letters, 2000. 7: p. 25-32.

5. Wu, C.K., et al., The crystal structure of augmenter of liver regeneration: $A$ mammalian FAD-dependent sulfhydryl oxidase. Protein Sci, 2003. 12(5): p. 1109-18.

6. Gross, E., et al., A new FAD-binding fold and intersubunit disulfide shuttle in the thiol oxidase Erv2p. Nat Struct Biol, 2002. 9(1): p. 61-7.

7. Chen, X., et al., The potentiation role of hepatopoietin on activator protein1 is dependent on its sulfhydryl oxidase activity. J Biol Chem, 2003.

278(49): p. 49022-30.

8. Thornton, J.M., Disulphide bridges in globular proteins. J Mol Biol, 1981. 151(2): p. 261-87.

9. Srinivasan, N., et al., Conformations of disulfide bridges in proteins. Int J Pept Protein Res, 1990. 36(2): p. 147-55.

10. Hofhaus, G. and T. Lisowsky, Sulfhydryl oxidases as factors for mitochondrial biogenesis. Methods Enzymol, 2002. 348: p. 314-24. 
11. Massey, V. and G. Palmer, On the existence of spectrally distinct classes of flavoprotein semiquinones. A new method for the quantitative production of flavoprotein semiquinones. Biochemistry, 1966. 5(10): p. 3181-9.

12. Massey, V., The chemical and biological versatility of riboflavin. Biochem Soc Trans, 2000. 28(4): p. 283-96.

13. Hoober, K.L. and C. Thorpe, Egg white sulfhydryl oxidase: kinetic mechanism of the catalysis of disulfide bond formation. Biochemistry, 1999. 38(10): p. 3211-7.

14. Williams, C.H., Jr., Lipoamide dehydrogense, glutathione reductase, thioredoxin reductase, and mercuric ion reductase-A family of flavoenzyme transhydrogenases in Chemistry nd Biochemistry of Flavoenzymes (Muller, F., ed). CRC Press, Chemistry and Biochemistry of Flavoenzymes, 1992: p. 121-211.

15. Page, C.C., C.C. Moser, and P.L. Dutton, Mechanism for electron transfer within and between proteins. Curr Opin Chem Biol, 2003. 7(5): p. 551-6.

16. Page, C.C., et al., Natural engineering principles of electron tunnelling in biological oxidation-reduction. Nature, 1999. 402(6757): p. 47-52.

17. Massey, V., et al., The production of superoxide anion radicals in the reaction of reduced flavins and flavoproteins with molecular oxygen. Biochem Biophys Res Commun, 1969. 36(6): p. 891-7.

18. Butler, J., W.H. Koppenol, and E. Margoliash, Kinetics and mechanism of the reduction of ferricytochrome $c$ by the superoxide anion. $\mathrm{J}$ Biol Chem, 1982. 257(18): p. 10747-50.

19. Ballou, D., G. Palmer, and V. Massey, Direct demonstration of superoxide anion production during the oxidation of reduced flavin and of its catalytic decomposition by erythrocuprein. Biochem Biophys Res Commun, 1969. 36(6): p. 898-904.

20. Engman, L., et al., Catalytic effects of glutathione peroxidase mimetics on the thiol reduction of cytochrome $c$. Chem Biol Interact, 1994. 93(2): p. 129-37.

21. Dikalov, S., V. Khramtsov, and G. Zimmer, Determination of rate constants of the reactions of thiols with superoxide radical by electron paramagnetic resonance: critical remarks on spectrophotometric approaches. Arch Biochem Biophys, 1996. 326(2): p. 207-18. 
22. Massey, V., C.H. Williams, Jr., and G. Palmer, The presence of S degreescontaining impurities in commercial samples of oxidized glutathione and their catalytic effect on the reduction of cytochrome $c$. Biochem Biophys Res Commun, 1971. 42(4): p. 730-8.

23. Raje, S. and C. Thorpe, Inter-domain redox communication in flavoenzymes of the quiescin/sulfhydryl oxidase family: role of a thioredoxin domain in disulfide bond formation. Biochemistry, 2003. 42(15): p. 4560-8.

24. Lange, H., et al., An essential function of the mitochondrial sulfhydryl oxidase Erv1p/ALR in the maturation of cytosolic Fe/S proteins. EMBO Rep, 2001. 2(8): p. 715-20.

25. Maret, W., Cellular zinc and redox states converge in the metallothionein/thionein pair. J Nutr, 2003. 133(5 Suppl 1): p. 1460S-2S.

26. Maret, W. and B.L. Vallee, Thiolate ligands in metallothionein confer redox activity on zinc clusters. Proc Natl Acad Sci U S A, 1998. 95(7): p. 347882.

27. Lu, H., et al., Functional TIM10 chaperone assembly is redox-regulated in vivo. J Biol Chem, 2004. 279(18): p. 18952-8.

28. Lutz, T., W. Neupert, and J.M. Herrmann, Import of small Tim proteins into the mitochondrial intermembrane space. EMBO J, 2003. 22(17): p. 4400-8.

29. Field, L.S., et al., Factors controlling the uptake of yeast copper/zinc superoxide dismutase into mitochondria. J Biol Chem, 2003. 278(30): p. 28052-9.

30. Han, D., E. Williams, and E. Cadenas, Mitochondrial respiratory chaindependent generation of superoxide anion and its release into the intermembrane space. Biochem J, 2001. 353(Pt 2): p. 411-6.

31. Hackenbrock, C.R., B. Chazotte, and S.S. Gupte, The random collision model and a critical assessment of diffusion and collision in mitochondrial electron transport. J Bioenerg Biomembr, 1986. 18(5): p. 331-68.

32. Cortese, J.D., A.L. Voglino, and C.R. Hackenbrock, Persistence of cytochrome c binding to membranes at physiological mitochondrial intermembrane space ionic strength. Biochim Biophys Acta, 1995. 1228(23): p. 216-228. 
33. Morgan, J.E. and M. Wikstrom, Steady-state redox behavior of cytochrome c, cytochrome a, and CuA of cytochrome c oxidase in intact rat liver mitochondria. Biochemistry, 1991. 30(4): p. 948-58.

34. Jones, D.P., Intracellular diffusion gradients of O2 and ATP. Am J Physiol, 1986. $250(5$ Pt 1): p. C663-75. 